\title{
Meta-analysis of arterial oxygen saturation monitoring by pulse oximetry in adults
}

\author{
Louise A. Jensen, RN, PhD, Judee E. Onyskiw, RN, PhD(c), and N.G.N. Prasad, PhD
}

Edmonton, Alberta, Canada

\begin{abstract}
OBJECTIVE: The purposes of the study were to: (1) describe the aggregate strength of the relationship of arterial oxygen saturation as measured by pulse oximetry with the standard of arterial blood gas analysis as measured by co-oximetry, (2) examine how various factors affect this relationship, and (3) describe an aggregate estimate of the bias and precision between oxygen saturation as measured by pulse oximetry and the standard in vitro measures.
\end{abstract}

DESIGN: A meta-analysis was conducted.

SAMPLE: Seventy-four studies from 1976 to 1994 met the inclusion criteria of: (1) adult study population, (2) quantitative analysis of empirical data, and (3) bivariate correlations or bias and precision estimates between pulse oximeter and co-oximeter values.

RESULTS: There were a total of 169 oximeter trials on 41 oximeter models from 25 different manufacturers. Studies were conducted in various settings with a variety of subjects, with most being healthy adult volunteers. The weighted mean $r$, based on 39 studies (62 oximeter trials) for which the $r$ statistic and number of data points were available, was 0.895 (var $[r]=0.014$ ). Based on 23 studies (82 oximeter trials) for which bias and precision estimates and number of data points were available, the mean absolute bias and precision were 1.999 and 0.233 , respectively. Several factors were found to affect the accuracy of pulse oximetry.

CONCLUSION: Pulse oximeters were found to be accurate within $2 \%( \pm 1$ SD) or $5 \%( \pm 2$ SD) of in vitro oximetry in the range of $70 \%$ to $100 \% \mathrm{SaO}_{2}$. In comparing ear and finger probes, readings from finger probes were more accurate. Pulse oximeters may fail to record accurately the true $\mathrm{SaO}_{2}$ during severe or rapid desaturation, hypotension, hypothermia, dyshemoglobinemia, and low perfusion states.

(Heart Lung ${ }^{\circledR}$ 1998;27:387-408)

W.

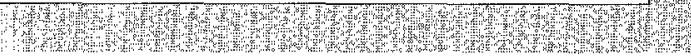

$\mathrm{T}$ he availability of oxygen, its transport and extraction at the tissue level, are vital factors to consider in caring for the acutely ill patient. ${ }^{1,2}$ The amount of oxygen reversibly bound to hemoglobin in arterial blood is referred to as the percentage of oxygen saturation of hemoglobin $\left(\mathrm{SaO}_{2}\right)$. Because $\mathrm{SaO}_{2}$ determines the majority of oxygen content, it is considered to be a clinically significant index of oxygenation. ${ }^{3}$ Although arterial

From the Faculty of Nursing and the Department of Mathematical Sciences, the University of Alberta, Edmonton, Alberta.

Reprint requests: Louise A. Jensen, RN, PhD, Professor, Faculty of Nursing. University of Alberta, 3rd Floor, Clinical Sciences Building, Edmonton, Alberta, T6G 2 G3.

Copyright (C) 1998 by Mosby, Inc

0147-9563/98/\$5.00 + $0 \quad \mathbf{2 / 1 / 9 2 9 5 8}$ blood gas $(\mathrm{ABG})$ analysis by co-oximetry has been the gold standard for measuring arterial oxygen saturation, it is invasive, involves repeated sampling of arterial blood, is costly, is time consuming, gives information only intermittently, and imposes a delay between sampling and the availability of results.

Noninvasive assessment of $\mathrm{SaO}_{2}$ has been made possible and simple by pulse oximetry. Measurement of oxygen saturation with use of the light absorption properties of hemoglobin was first proposed in the 1930s. ${ }^{4}$ Pulse oximetry evolved from 3 technologies: oximetry, plethysmography, and microprocessor-based instrumentation. ${ }^{5} \mathrm{~A}$ detailed history of the origins of this technique has been presented by Severinghaus and Astrup, 6,7 and Severinghaus and Honda. ${ }^{8}$ Matthes in 1936 is 
credited with developing the first oximeter to continuously monitor oxygen saturation with 2 wavelengths of light. ${ }^{7}$ This bulky, impractical sensor was later replaced in the 1940 s by Millikan with a lightweight ear sensor designed for aviators, ${ }^{5}$ and by Squire with a sensor applied to the web of the hand. ${ }^{9}$ Despite further refinements, oximeters were still awkward: difficult to use and to calibrate. Then in 1950, the development of the Clark polarographic electrode for measuring oxygen tension in blood samples led to a decline of interest in oximetry. ${ }^{2}$ Interest in oximetry was renewed in the 1960s when Hewlett-Packard produced the first commercial ear oximeter (HP 47201A). Featuring precalibration and a fixed path length, this oximeter solved many of the earlier problems. A major advance came in 1971 when Takuo Aoyagi led the way in the development of pulse oximetry based on pulsatile signals. This new concept took commercial form in the Minolta Oximeter. ${ }^{10}$ Next, Ohmeda BIOX and Nellcor ushered in a new era of microprocessor-based devices that were smaller and more convenient to use. ${ }^{5}$

Measurement of oxygen saturation with use of optical techniques is based on the Beer-Lambert law 4,11 that, "in order to determine the relative absorbance for each of a number of solutes, the transmission of an equal number of light wavelengths through the solution must be measured."12,p.45 Pulse oximetry combines the principles of spectrophotometry and plethysmography. Pulse oximeters measure the absorption of specific wavelengths of light in oxygenated hemoglobin as compared with that of reduced hemoglobin. 1-4,13,14 A probe, which can be clip-on or adhesive, reusable or disposable, is placed on a finger, ear lobe, nose, or a site with an adequate pulsating vascular bed. One side of the probe has 2 lightemitting diodes (LED) that transmit light wavelengths through pulsating arterial blood to a photodetector on the other side of the probe..$^{2-4,13-15}$ One LED transmits infrared light ( 900 to $940 \mathrm{~nm}$ ), which is absorbed by the oxyhemoglobin. The other wavelength emits red light $(660 \mathrm{~nm})$, which is absorbed by the reduced hemoglobin (deoxyhemoglobin). Pulsatile arterial blood during systole causes an influx of oxyhemoglobin to the tissue, absorbing more infrared light, thus allowing less light to reach the photodetector. Changes in optical density associated with systole become the basis for calculation of arterial oxygen saturation. ${ }^{2}$ The amplitude of light transmitted depends on the size of the arterial pulse change, the wave length of light used, and oxygen saturation of hemoglobin. 16,17
The microprocessor processes or filters the signals received and provides a digital display of $\mathrm{O}_{2}$ saturation, symbolized by $\mathrm{Spo}_{2}$.

Pulse oximetry remained a research tool for several years before clinical use began in the early 1980s. ${ }^{18}$ New $^{19}$ and others, ${ }^{5-9,15,18,20-32}$ have reviewed the literature on measuring arterial oxygen saturation by pulse oximetry. Technical advancements over recent years have refined pulse oximeters. Most pulse oximeters now provide a visual digital and waveform display, an audible display of arterial pulsations and heart rate, and a variety of sensors to accommodate individuals regardless of age, size, or weight. ${ }^{33}$ Consequently, pulse oximetry is used for continuous monitoring of arterial oxygen saturation in a variety of settings. It is now standard care in the operating room, $4,13,14,34-37$ in transfer from the operating room, $, 2,34,38$ in the postanesthesia care unit, 2,4,39-49 in the critical care unit, 2,4,27,50-56 for ventilatory management, ${ }^{57-59}$ and during various diagnostic and interventional procedures. ${ }^{2}, 34,58,60-66$ Pulse oximetry also is used in the emergency department for a variety of situations, ${ }^{3,17,67-70}$ such as during respiratory dysfunction, minor surgical procedures, treatments, or medication administration. Other settings that use pulse oximetry are pulmonary function testing laboratories $s^{9,71}$ and research laboratories for sleep apnea ${ }^{72-74}$ and exercise. ${ }^{75-77}$ Pulse oximetry is also used for periodic checks on medical and surgical units and in the labor and delivery unit. ${ }^{4,32}$ Emergency medical services also use pulse oximetry in the prehospital care setting. ${ }^{12,78,79}$ It is used in the field where assessment time is limited and resources are few. ${ }^{80}$ Pulse oximetry is also being evaluated for monitoring respiratory function in patients at home. $., 81,82$

\section{Accuracy and Precision of Pulse oximetry}

The degree of accuracy between pulse oximetry and in vitro methods was first reported in the literature as a correlation coefficient. Subsequently, Bland and Altman ${ }^{83}$ criticized the use of the correlation coefficient solely as a measure of agreement in determining accuracy, as the correlation procedures reflect only the relationship between 2 measures and may be influenced by variation between individuals. Bias and precision estimates then became the standard reported statistic when comparing the 2 methods. The bias, or systematic error, indicates the overestimation or underestimation of 1 method relative to the other; whereas the precision represents the variability or random error. Bias 
is estimated by the mean difference between the 2 measures and the precision by the standard deviation of the mean difference. ${ }^{83}$

Pulse oximetry has been reported to be accurate within $5 \% \pm 2 \%$ of in vitro oximetry. ${ }^{12}$ Pulse oximeters are most accurate in the $70 \%$ to $100 \%$ saturation range, where readings usually vary no more than $1 \%$ to $2 \%$ from the measurements obtained by standard blood gas analysis. ${ }^{9}$ Huffman ${ }^{13}$ stated that in the $80 \%$ to $100 \% \mathrm{SaO}_{2}$ range, a tolerance of $\pm 2 \%$ has become the accepted standard of performance. Although pulse oximetry is considered sufficiently accurate for many clinical purposes, there are limitations. Mengelkoch et $\mathrm{al}^{15}$ and Gaskin and Thomas ${ }^{31}$ reviewed studies that assessed the accuracy of pulse oximeters during exercise and concluded that pulse oximetry accuracy was variable, even among the same models. Thus comparing different models of pulse oximeters may be irrelevant if the internal algorithms differ. ${ }^{13} \mathrm{~A}$ single pulse oximeter cannot be considered a representative sample for that model, yet ranking accuracy of different pulse oximeters does not dismiss the efficacy of a particular pulse oximeter. ${ }^{13}$

Although most difficulties that result when using pulse oximeters produce a blank screen or an error message, some circumstances do produce false readings (Table I).$^{84}$ One limitation of pulse oximetry involves the arterial concentrations of carboxyhemoglobin $(\mathrm{CoHb})$ and methemoglobin (MetHb). Carboxyhemoglobin and MetHb have light absorption characteristics similar to oxyhemoglobin that can falsely elevate $\mathrm{SpO}_{2}$ levels. ${ }^{15,33,87}$

Intravenous dyes used in diagnostic and hemodynamic testing also can cause inaccurate (usually lower) estimates of $\mathrm{SpO}_{2}$. Furthermore, Gramlich, ${ }^{33}$ Durren, ${ }^{67}$ the American Association for Respiratory Care (AARC), ${ }^{81}$ and Cahan et ${ }^{191}$ suggested that the signal quality and the accuracy of $\mathrm{SpO}_{2}$ measurements are significantly affected in people with deeply pigmented skin. Yet, Mardirossian and Schneider ${ }^{14}$ and Bothma et $\mathrm{al}^{92}$ contend that pulse oximetry is not affected by racial skin pigmentations. Another source of error affecting pulse oximetry accuracy may be jaundice or bilirubin levels higher than $20 \mathrm{mg} / \mathrm{dL}$. ${ }^{14,17,78}$ On the other hand, Durren, ${ }^{67}$ the AARC, ${ }^{81}$ and Chelluri et al ${ }^{93}$ reported that hyperbilirubinemia was not found to alter $\mathrm{Spo}_{2}$ estimates when the oxygen saturation was more than $90 \%$. Finally, Coté et al ${ }^{94}$ found that brown-red nail polish interfered with pulse oximetry and should be removed before monitoring.

$\star 3,11,12,14,15,17,33,67,81,85,86$

$+3,14,17,18,67,81,88-90$
Table I

Factors affecting accuracy of pulse oximetry

\begin{tabular}{|c|c|}
\hline Sources of error & Effects on $\mathrm{Spo}_{2}$ \\
\hline $\mathrm{CoHb}$ & Overestimation \\
\hline Methemoglobinemia & Underestimation \\
\hline Methylene blue & Underestimation \\
\hline Skin pigmentation & $\begin{array}{l}\text { Signal loss, under- } \\
\text { estimation }\end{array}$ \\
\hline Hyperbilirubinemia & Overestimation \\
\hline Hypoxemia & Magnifies error \\
\hline Reduced perfusion & $\begin{array}{l}\text { Signal loss, under- } \\
\text { estimation }\end{array}$ \\
\hline $\begin{array}{l}\text { Reduced vascular } \\
\text { pulsations }\end{array}$ & Underestimation \\
\hline Anemia & Underestimation \\
\hline Motion artifact & $\begin{array}{l}\text { Signal loss, under- } \\
\text { estimation }\end{array}$ \\
\hline Ambient light & Underestimation \\
\hline
\end{tabular}

Two characteristics of pulse oximeters may cause errors in $\mathrm{SpO}_{2}$ estimates during hypoxic conditions. Algorithms used in pulse oximeters incorporate calibration curves derived from studies in which subjects' arterial oxygen saturation levels are $\geq 70 \%$. Also, during hypoxic conditions, the level of reduced hemoglobin is greater, which can magnify the error in the absorption ratio. ${ }^{15}$ Fanconi 95 reviewed the use of pulse oximeters during episodes of hypoxemia in 9 studies and found mixed results. Overall, few pulse oximeters performed well at oxygen saturation levels of less than $70 \% .{ }^{96-98}$ As well, the Technology Assessment Task Force of the Society of Critical Care Medicine, ${ }^{34}$ and the AARC ${ }^{81}$ suggested that for $\mathrm{SaO}_{2}$ levels less than $80 \%$, oximetry readings are less accurate because the oxyhemoglobin and deoxyhemoglobin are more similar in color at that level of saturation.

When peripheral tissue is poorly perfused, the signal from the pulsatile flow of blood will be impaired. Thus, if a peripheral pulse is absent (cardiac arrest) or of low amplitude (hypovolemia, hypotension, hypothermia, peripheral edema, alpha-adrenergic infusions, cardiogenic shock, or cardiac bypass), pulse oximetry readings will be intermittent or unavailable. $\neq$

Non-arterial pulses can also be detected, for example if the probe is secured too tightly, creating venous pulsations in the finger. ${ }^{78}$ Other situations

$\neq 12,14,15,17,18,24,33,67,78,81,99-109$ 
increasing venous pulsations are right-sided heart failure, tricuspid regurgitation, high positive end expiratory pressure, or the tourniquet effect of a blood pressure cuff above the probe. ${ }^{2,4,110}$ Barker et $\mathrm{al}^{97}$ also found that calibration curves of the pulse oximeters studied were changed greatly by sensor malpositioning. At low $\mathrm{SaO}_{2}$ values, only mild hypoxemia was indicated when, in fact, hypoxemia was profound.

There is some evidence that severe anemia affects pulse oximetry accuracy. ${ }^{111,112}$ An increased bias in both anemic and nonanemic subjects as the level of hypoxemia increases has been reported, but the error was greatest in anemic subjects with hemoglobin levels below $5 \mathrm{~g} / \mathrm{dL}^{4,111-113}$ The cause of the additional error due to anemia is not fully known, but may be due to photon scattering of light and a shift in red-light wavelength increasing its absorption. ${ }^{15}$

Another commonly encountered problem with pulse oximeters is motion artifact. ${ }^{\S}$ Although some pulse oximeters are designed to compensate for motion artifact, 116 it may result in a falsely low reading or signal loss. Occasionally, false pulse oximeter values are produced when there are significant amounts of ambient light on the sensor probe," such as sunlight, fluorescent lights, xenon lamps, surgical lamps, and infrared heating lamps. Finally, Schnapp and Cohen, ${ }^{4}$ and Mardirossian and Schneider ${ }^{14}$ reported that 60 -cycle interference caused by activated cautery tools renders pulse oximeters ineffective, displaying erroneous oxygen saturation values and sounding false alarms. Ralston et al ${ }^{119}$ found that 6 of 13 units tested gave erroneous readings, with no clear warning that the signal was unsatisfactory.

\section{Purpose of the Study}

There has been a rapid acceptance of pulse oximetry as a mode of monitoring patients in clinical settings with a consequent proliferation of manufacturers and models. Although there have been several integrative reviews on the accuracy of pulse oximetry, no meta-analysis of this data has been conducted. The purposes of this study were to: (1) describe the aggregate strength of the relationship of $\mathrm{SaO}_{2}$ as measured by pulse oximetry with the standard of $A B G$ analysis as measured by cooximeter, (2) examine how various factors affected this relationship, and (3) describe an aggregate estimate of the bias and precision between oxygen

$\S 1,3,4,14,15,17,33,78,81,114,115$

$\| 1,3,4,17,33,78,81,117,118$ saturation as measured by pulse oximetry and the standard in vitro measures.

\section{METHOD}

Sample. Published English articles on pulse oximetry were located by searching the computerized and citation indexes of literature in the health science disciplines. MEDLINE, EMBASE, HEALTHSTAR, and CINAHL databases were searched from 1970 to 1995 . Bibliographies also were reviewed to locate any studies not identified in the computerized searches. Published abstracts were retrieved when a published report was not found after a search of the author's(s') name(s). Each retrieved study was assessed independently by 2 investigators for inclusion, and $100 \%$ agreement was needed for inclusion in the final corpus of studies. Inclusion criteria were (1) quantitative analysis of empirical data, (2) bivariate correlations and/or bias and precision estimates between pulse oximeter and co-oximeter value estimates, and (3) adult population.

Procedure. An instrument was developed to rate scientific merit, because existing scales were inadequate for evaluating descriptive measurement studies (Table II). Assessment criteria included adequacy of measurement of the predictor (pulse oximeter) and criterion (co-oximeter) variables, and quality of the method, sample, and data analysis techniques. Twelve quality assessment criteria were rated on a 3-point scale (ie, acceptable, unacceptable, unable to assess). Criteria rated as acceptable were assigned a score of 1 and then summed to determine a total quality score. Two investigators independently rated the scientific merit of each study, achieving a 95\% agreement. The main discrepancy arose in assessing the degree of sample homogeneity. A consensus approach was used to resolve discrepancies and arrive at the final quality rating. Study quality was not used to exclude studies from the analysis; rather, studies were stratified post hoc to determine the effect of the quality rating on the correlation between the 2 methods. Methodological and substantive features of each study were coded and entered on a data collection form. Methodological features included the year of publication, type of study (ie, abstract or published study), quality rating, sample size, and number of data points. Substantive features included the type of study cohort, study setting, pulse oximeter model and probe location, co-oximeter and/or ABG analyzer model, the range and mean of arterial oxygen saturation levels, bivariate correlations and/or bias and preci- 


\section{Table II}

Research quality scoring form

Quality criteria

\section{Predictor and criterion variables}

(1) Definition of predictor variable (model, probe type and location of sensor)

(2) Definition of criterion measure (ABG analyzer, $A B G$ source)

(3) Reliability of criterion variable

\section{Methodological criteria}

(1) Predictor variable measured reliably (inter- and intra-rater reliably)

(2) Criterion variable measured reliably (interand intra-rater reliably)

(3) Measurements unbiased (concurrent and/or predictive)

\section{Sampling criteria}

(1) Sample size (data points)

(2) Sample unbiased (homogeneity, confounding characteristics, stability)

(3) Cross-validation studies

Data analysis criteria

(1) Validity estimates (method, technique, accounts for confounding factors)

(2) Bias and precision estimates

\section{Acceptable}

Unacceptable

Unable to

assess

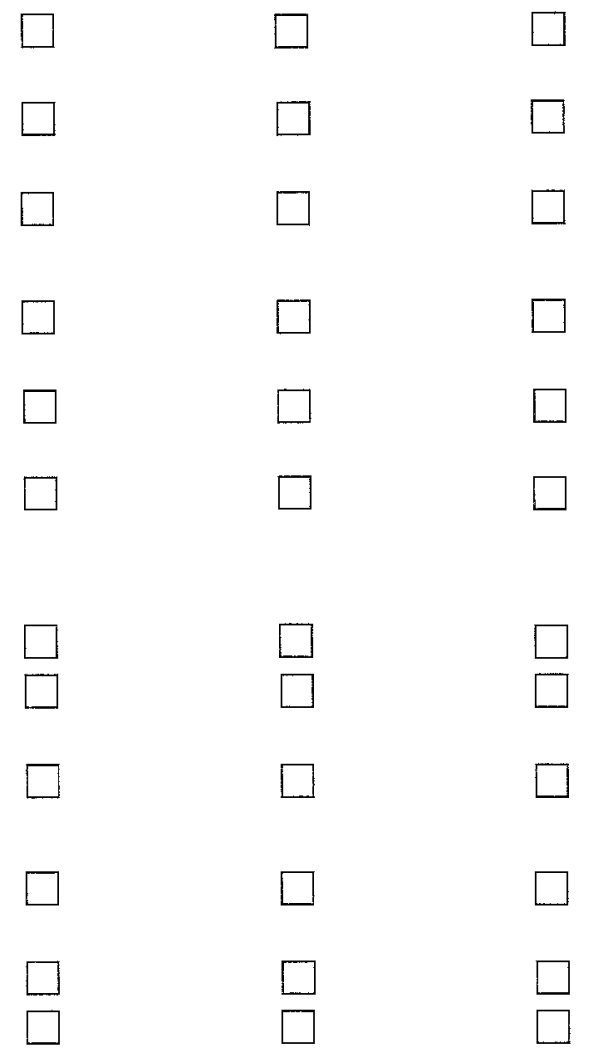

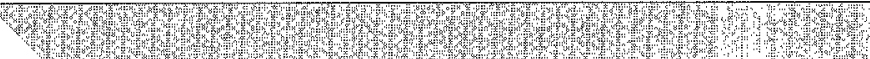

sion estimates between the pulse oximeter and cooximeter values, as well as specific conditions or factors that affect pulse oximetry accuracy (skin pigmentation, hypoxia, temperature, perfusion, dyshemoglobinemia, hyperbilirubinemia).

Analysis. The Hunter and Schmidt ${ }^{120}$ method was used to conduct the meta-analysis. First, a weighted mean correlation was calculated as the sum of all primary study correlations, divided by the sum of the sample size from each study. Next, the overall observed variance was calculated as the sample size-weighted sum of the squared deviation from this average correlation. Both these statistics were sample weighted such that studies based on larger samples were given more weight than studies based on smaller samples. Sampleweighting was based on the number of data points from repeated measurements. Second, a weightedmean bias estimate was calculated as the sum of the weighted absolute mean bias values reported, divided by the sum of the primary study weights. The weight was calculated as the reciprocal of the variance components estimates. Finally, Hunter and Schmidt ${ }^{120}$ recommend removing the variance caused by sampling error, because sampling error normally affects the variance across study coefficients, whereas other artifacts, such as measurement error and range restriction, affect the variance within the study coefficients. If sampling error accounts for more than $75 \%$ of the overall observed variance, then the correlation coefficients are thought to be constant across studies. ${ }^{120}$ Therefore, the amount of variance among the study correlations remaining after removing the variance for sampling error was compared with the overall observed variance. Because the variance caused by sampling error failed to account for most of the overall observed variance, it was concluded that 
correlations were not constant across studies, and a search for confounding variables was undertaken.

\section{RESULTS}

Characteristics of studies reviewed. Of the 247 articles retrieved, 150 studies examined the accuracy of pulse oximetry. Of these, 74 studies met the inclusion criteria. Studies were published from 1976 to 1994 . Nine studies were published in the late 1970s, 43 studies were published in the 1980s, and 22 studies were published in the early 1990s. More than $86 \%$ of the studies were articles; $14 \%$ of the studies were abstracts. All abstracts that had no corresponding published article were retained for the analysis. The quality rating of the 74 studies ranged from 3 to 11 , with a mean of $8.0(\mathrm{SD}=1.75)$. Studies received a lower quality rating for several reasons. Studies reported the reliability of the predictor variable, but failed to report the reliability of the criterion variable. Forty-four studies reported the bivariate correlation between the predictor and the criterion variable, whereas 27 studies reported bias and precision estimates. In addition, studies rarely conducted cross-validation studies or included reliability estimates.

A summary of the studies ${ }^{121-194}$ included in the meta-analysis is presented in Table III. Of the 74 studies, 24 studies tested 1 oximeter, and 50 studies tested from 2 to 20 different oximeter models. In the 74 studies, there were a total of 169 oximeter trials conducted on various combinations of oximeter models. There were 25 different oximeter manufacturers with a total of 41 different models (Table IV). More than $69 \%$ of the oximeter trials tested finger probes, $23.7 \%$ tested ear probes, $4.1 \%$ tested multiple probes, and the remainder $(0.6 \%)$ tested forehead probes.

A repeated-measures design was most frequently used in the studies. Consequently, authors reported both the sample size and the number of data points (paired samples) measured. Studies that examined more than 1 oximeter often used different numbers of subjects and data points for each oximeter tested (Table III). In the 169 oximeter trials from the 74 studies, sample size ranged from 5 to 183 subjects, with a mean of $29.43(\mathrm{SD}=32.37$ ) and a mode of 8.00 , and data points ranged from 13 to 524 , with a mean of $110.66(\mathrm{SD}=01.03)$ and a mode of 40.00 . Although a variety of subjects were used, most were healthy adult volunteers $(25.7 \%)$. There were also a variety of hospital in-patients such as respiratory patients $(20.3 \%)$, thoracic surgical patients $(5.4 \%)$, cardiac surgical patients $(13.5 \%)$, critically ill patients $(16.2 \%)$, and patients with more than 1 medical condition ( $10.8 \%)$. The remaining studies involved individuals with sleep disorders $(1.4 \%)$ and athletes $(5.4 \%)$. Studies were conducted in a variety of settings: laboratories $(44.6 \%)$, intensive care units $(27.0 \%)$, various hospital inpatient units $(17.6 \%)$, and operating rooms $(10.8 \%)$.

Most studies monitored or controlled the level of oxygenation in their subjects. Fifty-nine of the 74 studies reported subjects' lowest level of oxygenation, ranging from $36 \%$ to $96 \%(\mathrm{M}=70.29 \%, \mathrm{SD}=$ 15.59). Fifty-seven studies reported subjects' highest level of oxygenation, ranging from $70 \%$ to $100 \%$ $(\mathrm{M}=98.53 \%, \mathrm{SD}=4.29)$. There was a mean $\mathrm{SaO}_{2}$ of $90.05 \%$ in the 20 studies that reported this value. $\mathrm{SaO}_{2}$ standards were the Instrumentation Laboratory IL182 (1.4\%), IL282 (37.8\%), or IL482 $(4.1 \%)$ cooximeters; Corning C-2500 (6.8\%) co-oximeter; Radiometer OSM-1 (1.4\%), OSM-2 (13.5\%), OSM-3 (9.5\%) co-oximeters; and the American Optical Unistat $(2.7 \%)$ co-oximeter; the remainder did not specify the model (5.4\%). In $47.3 \%$ of the 74 studies, an $\mathrm{ABG}$ analyzer was used to measure $\mathrm{SaO}_{2}$ or in conjunction with a co-oximeter. ABG analyzers consisted of the Radiometer ABL2 (5.4\%), ABL3 (2.7\%), ABL4 (1.4\%), ABL300 (1.4\%), BMS3 (1.4\%), BMS-MK2 (1.4\%) analyzers; Instrumentation Laboratory IL1 13 (4.1\%), IL313 (2.7\%), IL813 (2.7\%), IL1312 (2.7\%) analyzers; Ciba Corning 168 (1.4\%), C-175 (5.4\%), C-178 $(5.4 \%), C-278(1.4 \%)$ analyzers, or was not specified (8.1\%).

Meta-analyses of pulse oximetry accuracy. Not all of the 74 studies included in the meta-analysis provided data on the number of subjects and data points (paired samples), as well as the correlation coefficient $(r)$ and bias and precision estimates (Table V). The unweighted mean $r$, based on the 39 studies (62 oximeter trials) for which the $r$ statistic and the number of data points were available, was 0.910 (var $[r]=0.011$ ); the weighted mean $r$ was 0.895 (var $[r]=0.014$ ). A ranking of the 21 pulse oximeters used in these studies by correlation with $\mathrm{SaO}_{2}$ is presented in Table VI. Based on 23 studies (82 oximeter trials) for which bias and precision estimates and the number of data points were available, the absolute mean bias was $1.99 \% \pm 0.23$.

In addition, the mean correlation was estimated based on the rating of study quality. Studies having a quality rating $\geq 9$ out of 12 (22 studies, 43 oximeter trials) had an unweighted mean $r$ of 0.908 (var $[r]=0.011$ ) and a weighted mean $r$ of 0.883 (var $[r]=0.016]$. To assess whether the recency of studies influenced the accuracy of pulse oximetry, studies were grouped according to the decade of publication. The unweighted and weighted mean 


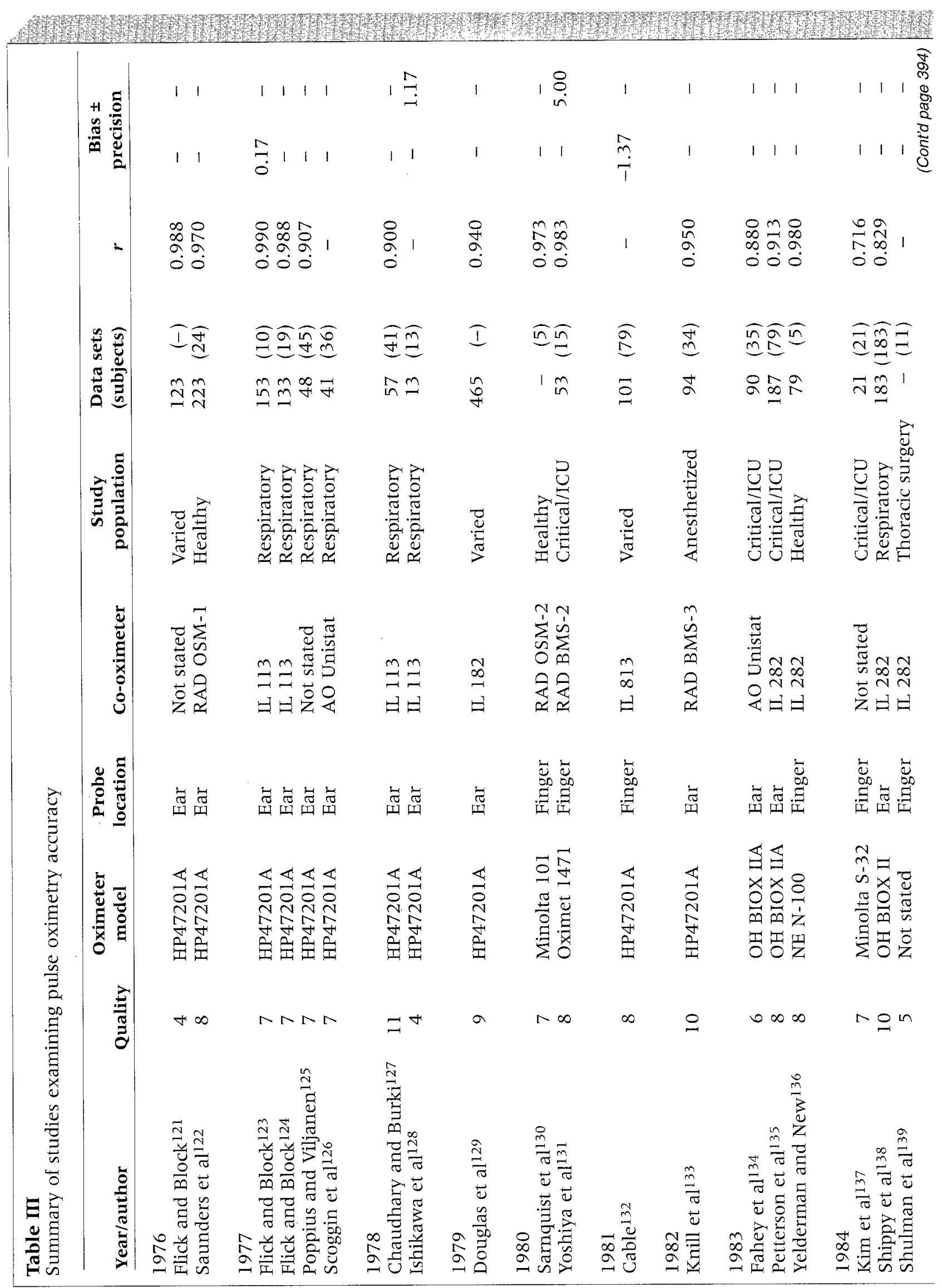




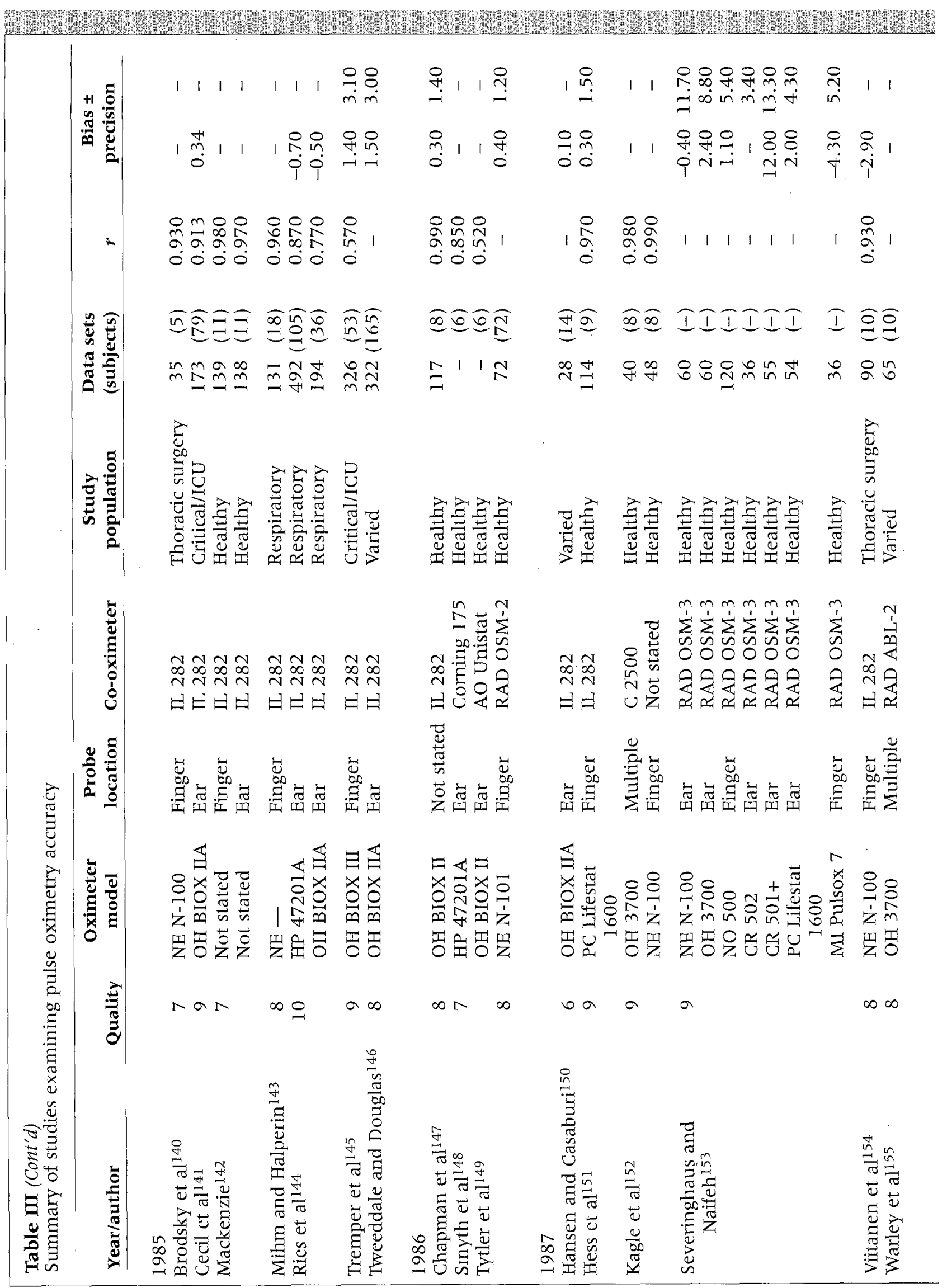




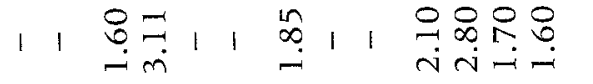

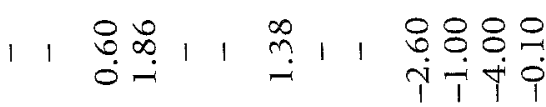

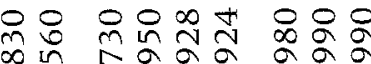

ơ

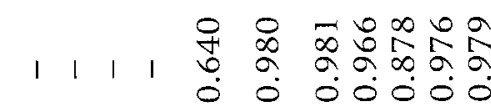

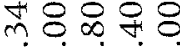

îं i

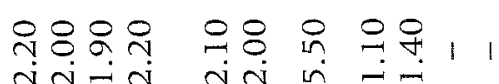

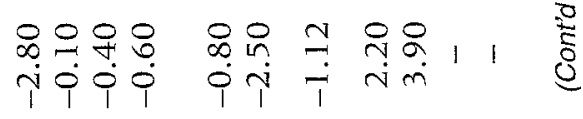

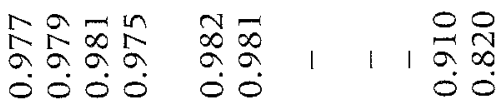

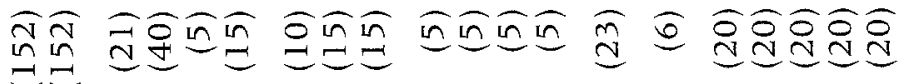

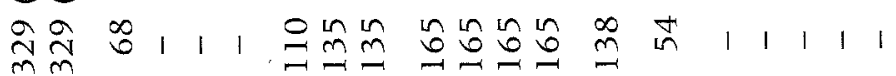

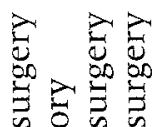

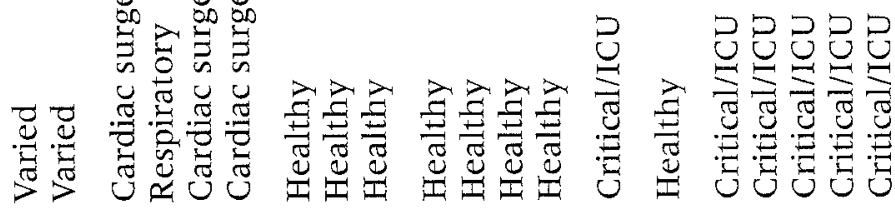

$\sum_{\substack{\infty \\ N}}^{N}$

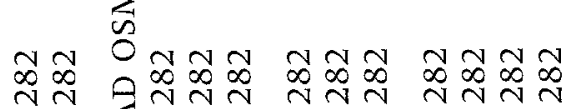

ZN

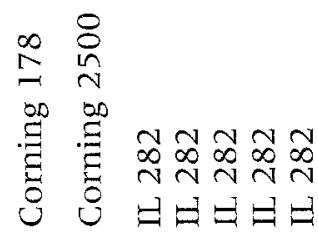

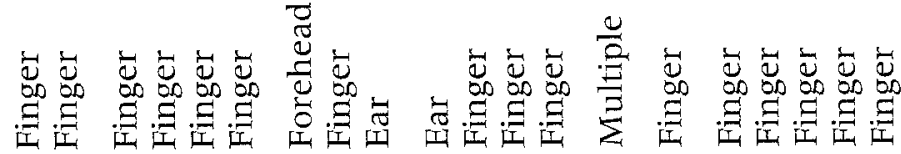

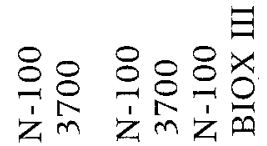

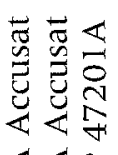

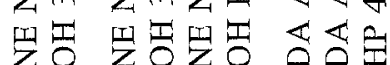

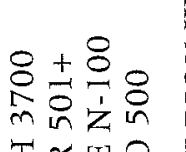

要

$a \quad 00 \infty \quad a \circ \stackrel{0}{\circ}$

$\infty \propto \infty$

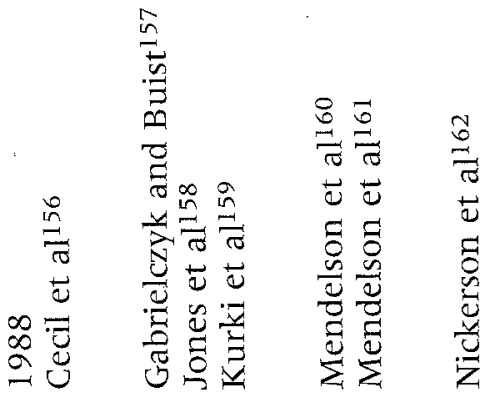

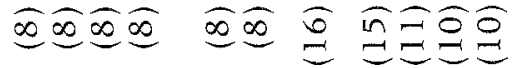

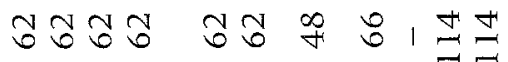

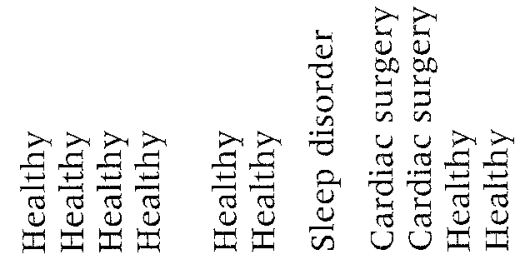

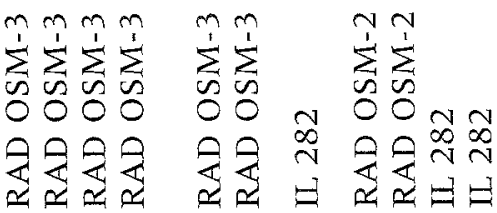

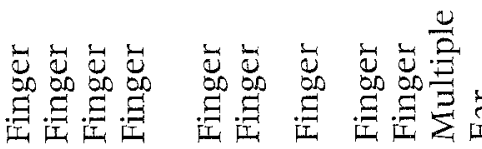




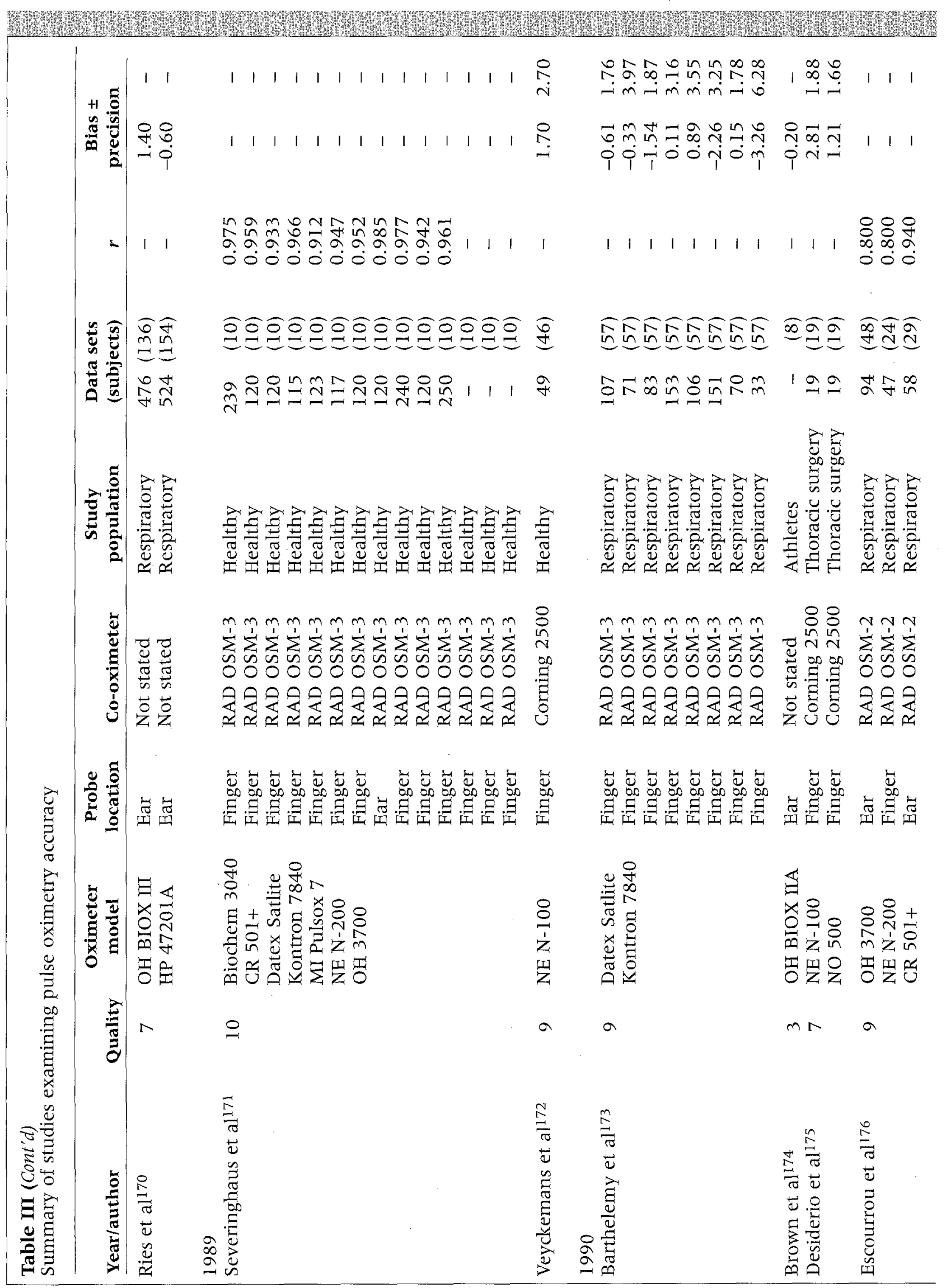




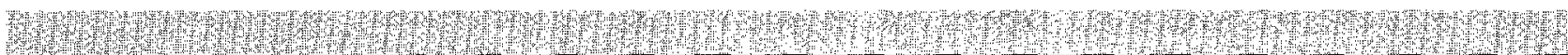

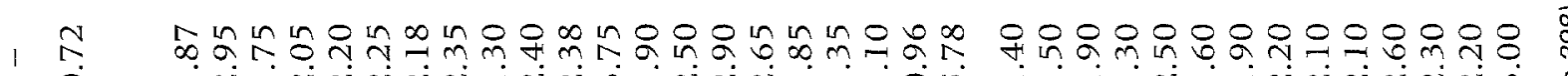

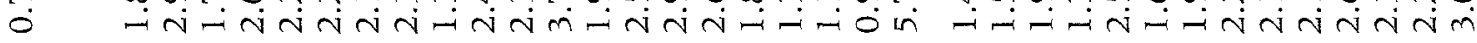

茂

i

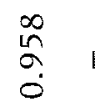

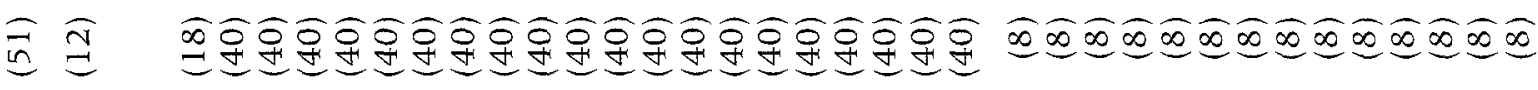

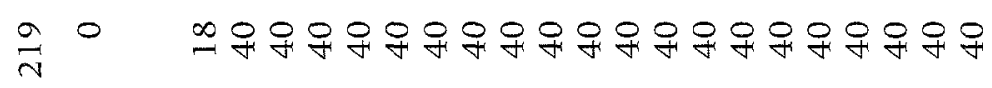

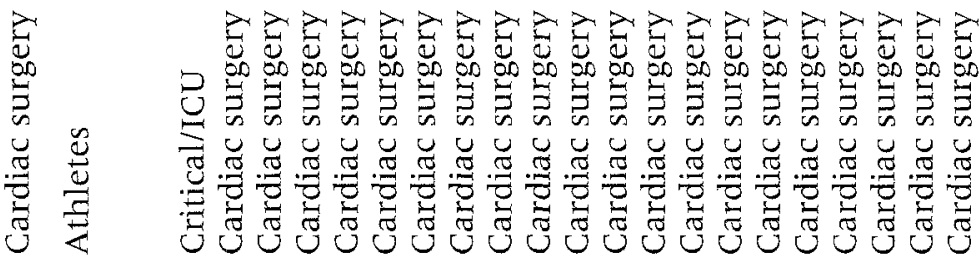

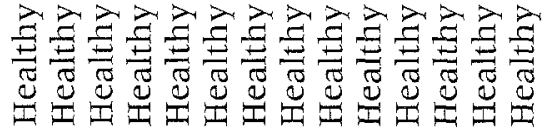

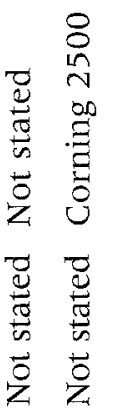

$\sum_{\substack{n \\ 0}}^{m}$

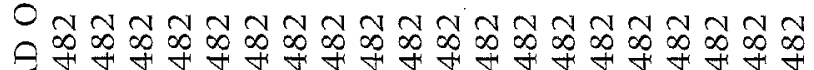

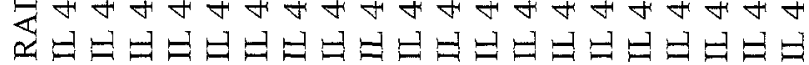

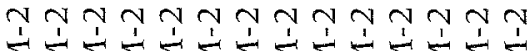

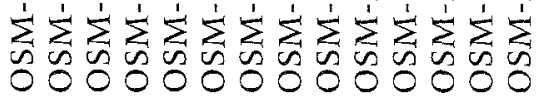

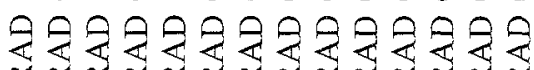

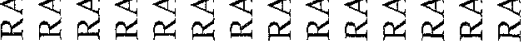

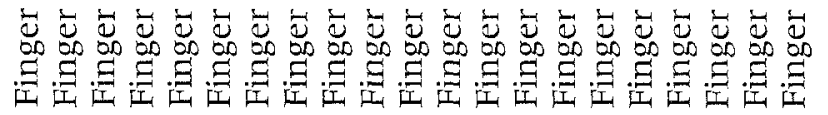

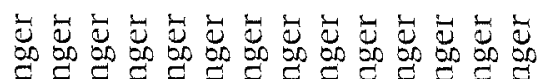

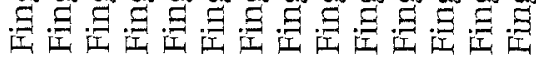

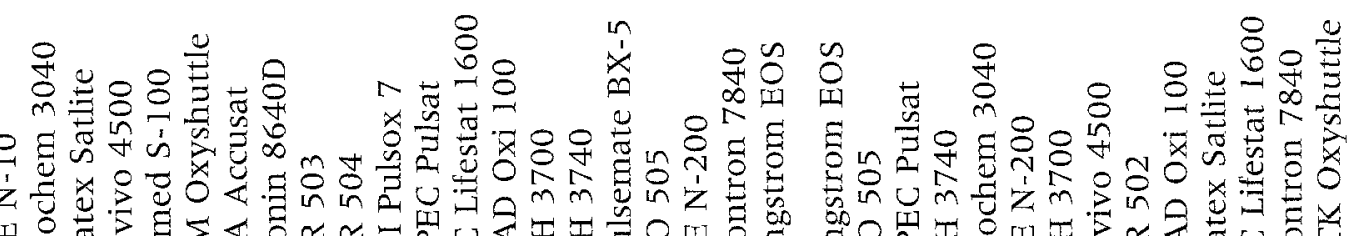




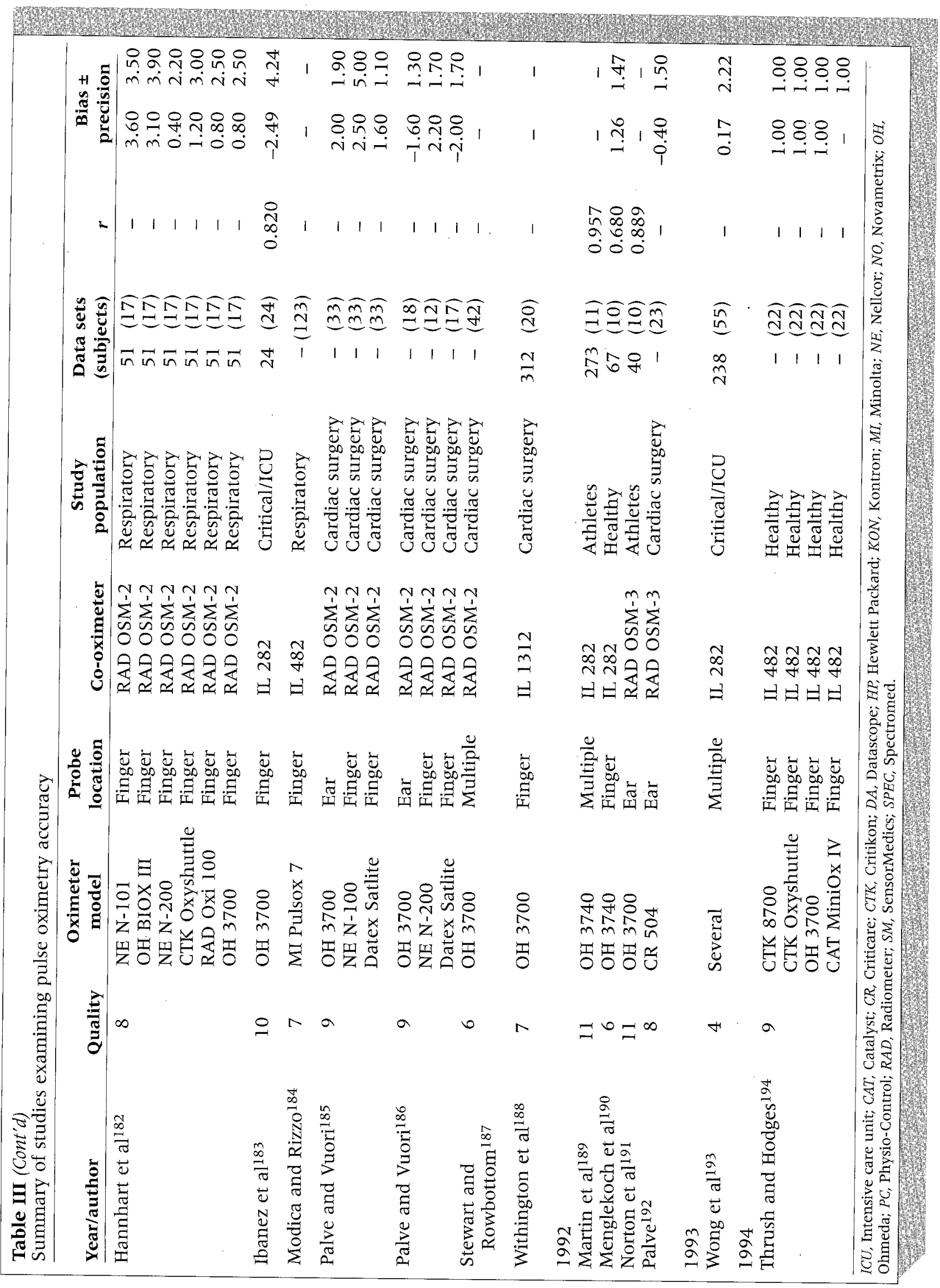


correlation statistic for studies published in the 1970s ( 7 studies, 7 oximeter trials) was 0.955 (var [r] $=0.002)$ and $0.959(\operatorname{var}[r]=0.005)$, respectively; in the 1980s (26 studies, 47 oximeter trials) was 0.913 $(\operatorname{var}[r]=0.012)$ and 0.882 (var $[r]=0.0170)$, respectively; and in the 1990s (6 studies, 8 oximeter trials) was $0.855(\operatorname{var}[r]=0.010)$ and $0.899(\operatorname{var}[r]=0.008)$, respectively. Correlations of pulse oximetry with $\mathrm{SaO}_{2}$ were estimated by type of subject (Table VII). The highest correlation was in healthy adult volunteers $(r=0.957)$, with the lowest in critically ill patients $(r=0.760)$.

Four studies (6 oximeter trials) compared pulse oximetry accuracy with ear and finger probes. Of these, only 3 studies ( 3 oximeter trials) provided the data points and the correlational statistic (Table VIII). For oximeters using the ear probe, the unweighted and weighted mean $r$ was 0.938 (var $[r]$ $=0.002$ ) and 0.934 (var $[r]=0.001$ ), respectively. For oximeters using the finger probe, the unweighted and weighted mean $r$ was $0.963(\operatorname{var}[r]=0.001)$ and 0.967 (var $[r]=0.001)$, respectively. Finger probes were found to have a statistically significant higher correlation with $\mathrm{SaO}_{2}$ than ear probes $(\mathrm{Z}=5.21, P<$ .0001 ).

Meta analysis of factors affecting pulse oximetry accuracy. Many factors affect the accuracy of pulse oximetry. Only 6 of those factors, however, were examined in a sufficient number of oximeter trials to warrant subanalyses (Table IX).

Hypoxia. Fifteen studies (61 oximeter trials), conducted between 1985 and 1991, tested the accuracy of pulse oximetry during hypoxic conditions. Of these, only 5 studies ( 15 oximeter trials) provided both the correlation statistic and the number of data points. An unweighted and weighted mean $r$ of $0.924(\operatorname{var}[r]=0.008)$ and $0.938(\operatorname{var}[r]$ $=0.006$ ), respectively, were found during hypoxic conditions (range, $67.6 \%$ to $87.8 \% \mathrm{SaO}_{2}$ ). Subjects were hypoxic due to surgery, deteriorating health, or induced by rebreathing $\mathrm{CO}_{2}$.

The Mihm and Halperin ${ }^{143}$ regression analysis of 23 data sets from 3 patients, in whom arterial desaturation of less than $70 \%$ developed, demonstrated a correlation of 0.99 with use of the Nellcor (model not specified) pulse oximeter. Kagle et al ${ }^{152}$ reported a correlation of 0.96 with use of an Ohmeda 3700 (ear probe) oximeter, but a correlation of 0.78 with use of an Ohmeda 3700 (finger probe) oximeter when the $\mathrm{SaO}_{2}$ was below $90 \%$. Brodsky et al ${ }^{140}$ found the Nellcor $\mathrm{N}-100$ was accurate in hypoxic ranges of $79 \%$ to $90 \%$ during 1 -lung ventilation. Tremper et $\mathrm{al}^{1}{ }^{145}$ in contrast, found a correlation of 0.65 for the Ohmeda BIOX III (finger probe) in

\begin{tabular}{|c|c|}
\hline \multicolumn{2}{|c|}{$\begin{array}{l}\text { Table IV } \\
\text { Manufacturers and models of pulse } \\
\text { oximeters }\end{array}$} \\
\hline Manufacturers & Models \\
\hline Biochem & $\begin{array}{l}\text { Microspan 3040, } \\
\text { Ox2000 }\end{array}$ \\
\hline Bird & 4400 \\
\hline Catalyst & Miniox IV \\
\hline Colin & Pulsemate BX-5 \\
\hline Criticare & $504,503,502,501+$ \\
\hline Critikon & $\begin{array}{l}\text { Oxyshuttle, Dinamap } \\
\text { Plus } 8700 \text {, Oxytrak }\end{array}$ \\
\hline Datascope & Accusat \\
\hline Datex & Satlite \\
\hline Engstrom & EOS \\
\hline Hewlett Packard & $47201 \mathrm{~A}$ \\
\hline Invivo & 4500 \\
\hline Kontron & 7840 \\
\hline Minolta & Pulsox 7, S-32, 101 \\
\hline Nellcor & $\mathrm{N}-10, \mathrm{~N}-100, \mathrm{~N}-101, \mathrm{~N}-200$ \\
\hline Nonin & $8604 \mathrm{D}$ \\
\hline Novametrix & 500,505 \\
\hline Ohmeda & $\begin{array}{l}\text { BIOX II, ПIA, III, } 3700 \text {, } \\
3740\end{array}$ \\
\hline Oximet & 1471 \\
\hline Physio-Control & Lifestat 1600 \\
\hline PPG-Hellige & 4500 \\
\hline Puritan & 240 \\
\hline Radiometer & OXI \\
\hline SensorMedics & Oxyshuttle \\
\hline SiMed & S- 100 \\
\hline Spectromed & Pulsat \\
\hline
\end{tabular}

hypoxic ranges of $80.9 \%$ to $95.0 \%$. Severinghaus et al ${ }^{171}$ studied the accuracy of pulse oximeters from 14 manufacturers during brief hypoxic episodes $\left(45.0 \%\right.$ to $\left.90.0 \% \mathrm{SaO}_{2}\right)$. Although the correlations were strong, the data showed substantial differences in bias and precision estimates between pulse oximeters at low saturation; the most common being an underestimation of saturation and failing precision.

Dyshemoglobinemia. Five studies $(6$ oximeter trials) examined the effects of dyshemoglobinemia on pulse oximetry accuracy. The number of data points examined ranged from 33 to $326(\mathrm{M}=103$, $\mathrm{SD}=114.88$ ). The unweighted mean $r$ was 0.817 (var $[r]=0.028$ ); the weighted mean $r$ was 0.717 (var $[r]$ $=0.717$ ). Carboxyhemoglobin levels ranged from $5.87 \%$ to $9.10 \%$. The Douglas et al ${ }^{129}$ results indicated that the HP 47201A ear oximeter can measure 
Table V

No. of studies/No. of oximeter trials

\begin{tabular}{|c|c|c|}
\hline & Reported No. of subjects & Reported No. data points \\
\hline Reported correlation & 42 Studies/71 oximeter trials & 39 Studies/62 oximeter trials \\
\hline Reported bias and precision & 29 Studies/103 oximeter trials & 23 Studies/82 oximeter trials \\
\hline $\begin{array}{l}\text { Reported correlation, bias } \\
\text { and precision }\end{array}$ & 9 Studies/14 oximeter trials & 9 Studies/27 oximeter trials \\
\hline
\end{tabular}

Table VI

Ranking of 21 pulse oximeters by correlation with oxygen saturation

\begin{tabular}{|c|c|c|c|c|c|}
\hline Oximeter model & $\begin{array}{c}\text { Type of } \\
\text { probe }\end{array}$ & $\begin{array}{c}\text { No. } \\
\text { oximeter } \\
\text { trials }\end{array}$ & $\begin{array}{c}\text { Total No. } \\
\text { subjects }\end{array}$ & $\begin{array}{c}\text { Total No. } \\
\text { data } \\
\text { points }\end{array}$ & $r$ \\
\hline Datascope Accusat & Finger/flex & 2 & 25 & 245 & 0.986 \\
\hline Oximet 1471 & Finger & 1 & 15 & 53 & 0.983 \\
\hline Novametrix 500 & Finger & 1 & 8 & 62 & 0.981 \\
\hline Physio-Control Lifestat 1600 & Ear/finger & 3 & 27 & 120 & 0.977 \\
\hline Puritan 240 & Finger & 1 & 10 & 240 & 0.977 \\
\hline Biochem Microspan 3040 & Finger & 1 & 10 & 239 & 0.975 \\
\hline Kontron 7840 & Finger & 1 & 10 & 115 & 0.966 \\
\hline SiMed S-100 & Finger & 1 & 10 & 250 & 0.961 \\
\hline Radiometer OXI & Finger & 2 & 18 & 182 & 0.955 \\
\hline Criticare $501+$ & Ear/finger & 2 & 39 & 178 & 0.953 \\
\hline Datex Satlite OS-103 & Finger & 2 & 18 & 182 & 0.950 \\
\hline Hewlett Packard 47201A & Ear & 10 & 293 & 1923 & 0.938 \\
\hline Minolta Pulsox 7 & Finger & 2 & 18 & 185 & 0.934 \\
\hline Nellcor N-200 & Finger & 2 & 34 & 164 & 0.905 \\
\hline Ohmeda BIOX 3740 & Finger/multiple & 2 & 21 & 340 & 0.902 \\
\hline Ohmeda BIOX II & Ear & 2 & 191 & 300 & 0.892 \\
\hline Nellcor $\mathrm{N}-100$ & Finger & 6 & 201 & 649 & 0.869 \\
\hline Ohmeda BIOX ШA & Ear & 5 & 239 & 758 & 0.858 \\
\hline Ohmeda BIOX 3700 & Ear/finger & 9 & 276 & 877 & 0.781 \\
\hline Minolta S-32 & Finger & 1 & 21 & 21 & 0.716 \\
\hline Ohmeda BIOX III & Finger/multiple & 2 & 76 & 464 & 0.591 \\
\hline
\end{tabular}

$\mathrm{SaO}_{2}$ in the range of $65 \%$ to $100 \%$ with an accuracy of $\pm 4 \%$, if the concentration of $\mathrm{CoHb}$ is less than $3 \%$. The oximeter was found to be sensitive to $\mathrm{CoHb}$, progressively overestimating arterial saturation as $\mathrm{CoHb}$ concentration increased from $0 \%$ to $18 \%$. Similarly, Shippy et al ${ }^{138}$ found that the Ohmeda BIOX II ear oximeter provided accurate, continuous measurement of patients' oxygenation status in the absence of elevated $\mathrm{CoHb}$ levels in the blood. When the CoHb level was more than $3 \%$ in 129 paired samples, the Ohmeda BIOX II ear oximeter progressively overestimated $\mathrm{SaO}_{2}$. Tashiro et al 164 reported $\mathrm{CoHb}$-induced errors in healthy volunteers with use of the Ohmeda BIOX 3700 . When the percentage fraction of $\mathrm{CoHb}$ was increased, the $\mathrm{SaO}_{2}$ was overestimated. Finally, Powers et al ${ }^{169}$ evaluated the Ohmeda 3700 (finger and ear probes) and BIOX Ila (ear probe) pulse oximeters during cycle ergometer in healthy smoking and nonsmoking volunteers, and suggested that pulse oximetry is useful in estimating changes in $\mathrm{SaO}_{2}$ during exercise in subjects with $\mathrm{CoHb}<3 \%$. Trem- 
Table VII

Correlation of pulse oximetry with oxygen saturation by type of subject

\begin{tabular}{|c|c|c|c|c|c|}
\hline $\begin{array}{l}\text { Type of } \\
\text { subject }\end{array}$ & $\begin{array}{r}\text { No. of } \\
\text { studies }\end{array}$ & $\begin{array}{c}\text { Total No. } \\
\text { of subjects }\end{array}$ & $\begin{array}{l}\text { Total No. of } \\
\text { data points }\end{array}$ & $\begin{array}{c}\text { No. of } \\
\text { oximeter trials }\end{array}$ & $r$ \\
\hline Healthy adult volunteers & 13 & 318 & 3683 & 32 & 0.957 \\
\hline Anesthetized patients & 1 & 34 & 94 & 1 & 0.950 \\
\hline Athletes & 2 & 21 & 313 & 2 & 0.948 \\
\hline Thoracic surgical patients & 2 & 15 & 125 & 2 & 0.930 \\
\hline Cardiac surgical patients & 2 & 72 & 287 & 2 & 0.904 \\
\hline Respiratory patients & 8 & 558 & 1590 & 11 & 0.880 \\
\hline Critically ill/ICU patients & 8 & 329 & 1012 & 8 & 0.760 \\
\hline
\end{tabular}

\section{Table VIII}

Probe location

\begin{tabular}{lcccc}
\hline Location & $\begin{array}{c}\text { No. of } \\
\text { studies }\end{array}$ & $\begin{array}{c}\text { No. of } \\
\text { oximeters }\end{array}$ & $\begin{array}{c}\text { Mean } \\
\text { unweighted } r \\
(\text { Var } r)\end{array}$ & $\begin{array}{c}\text { Mean } \\
\text { weighted } r \\
(\text { Var } r)\end{array}$ \\
\hline Ear & 3 & 3 & $0.938(0.002)$ & $0.934(0.001)$ \\
Finger & 3 & 3 & $0.963(0.001)$ & $0.967(0.001)^{*}$ \\
\hline${ }^{*} Z=5.21 ; P<.0001$. & & & &
\end{tabular}

\section{Table IX}

Studies examining factors that affect pulse oximeter accuracy

\begin{tabular}{lccc}
\hline Condition & \multicolumn{1}{c}{$\begin{array}{c}\text { No. of studies/ } \\
\text { No. of oximeter } \\
\text { trials }\end{array}$} & $\begin{array}{c}\text { Mean } \\
\text { unweighted } r \\
\text { (Var } r)\end{array}$ & $\begin{array}{c}\text { Mean } \\
\text { weighted } r \\
\text { (Var } r)\end{array}$ \\
\hline Hypoxia & 5 Studies/15 oximeter trials & $0.924(0.008)$ & $0.938(0.006)$ \\
Perfusion & 3 Studies/3 oximeter trials & $0.717(0.049)$ & $0.582(0.004)$ \\
Dyshemoglobinemia & 5 Studies/6 oximeter trials & $0.817(0.028)$ & $0.717(0.035)$ \\
Temperature & 3 Studies/3 oximeter trials & $0.760(0.043)$ & $0.665(0.024)$ \\
Skin pigmentation & 1 Study/2 oximeter trials & $0.800(0.0002)$ & $0.800(0.0002)$ \\
Hyperbilinubinemia & 1 Study/1 oximeter trial & 0.850 & -
\end{tabular}

per et al ${ }^{145}$ studied the effects of hemodynamics on the accuracy of the Ohmeda BIOX III (finger probe) in 326 paired samples from critically ill patients and concluded that conditions of extreme anemia may lead to a weakened pulse-absorbance signal.
Perfusion. Although 9 studies ( 33 oximeter trials) examined the effects of perfusion states on pulse oximetry, only 3 studies ( 3 oximeter trials) provided a correlation statistic. The number of data points examined were 9,12 , and 326 , respectively. The unweighted and weighted mean $r$ were 0.717 
$(\operatorname{var}[r]=0.049)$ and $0.582(\operatorname{var}[r]=0.004)$, respectively. Fahey et al ${ }^{134}$ reported that when the Ohmeda BIOX IIA pulse oximeter alarm sounded for systolic blood pressure $<100 \mathrm{~mm} \mathrm{Hg}$ in 12 paired samples, the accuracy decreased. Tremper et al ${ }^{145}$ suggested that at extremes of systemic resistance, the Ohmeda BIOX III oximeter may be unable to estimate $\mathrm{SaO}_{2}$. In contrast, $\mathrm{Mihm}$ and Halperin ${ }^{143}$ obtained reliable data with use of a Nellcor pulse oximeter (model not specified) in 9 out of 131 data sets in which the mean arterial pressure was $<60 \mathrm{~mm} \mathrm{Hg}$. Clayton et al ${ }^{195}$ recom mended the use of finger probes, rather than ear, nose, or forehead probes, for patients with poor peripheral perfusion.

Temperature. Of the 5 studies ( 7 oximeter trials) that examined the effect of temperature on pulse oximetry accuracy, only 3 studies ( 3 oximeter trials) provided the correlation statistic. The mean temperature range in these studies was $28.6^{\circ} \mathrm{C}$ to $34.8^{\circ} \mathrm{C}$. The unweighted mean $r$ was 0.760 (var $[r]=$ 0.043 ), whereas the weighted mean $r$ was 0.665 (var $[r]=0.024)$. Under conditions of hypothermia $(T<$ $35^{\circ} \mathrm{C}$ ), Tremper et al ${ }^{145}$ found that the Ohmeda BIOX III (finger probe) oximeter had difficulty processing a reliable signal. Gabrielczyk and Buist ${ }^{157}$ evaluated the accuracy of the Nellcor N-100 (finger probe) in hypothermic patients (core temperature $\leq 35^{\circ} \mathrm{C}$ ) after cardiac surgery and found that $\mathrm{SaO}_{2}$ was overestimated compared with in vitro oximetry, with a mean bias of $0.6 \%$. In contrast, Peters et al, ${ }^{177}$ in 84 paired data sets, found high correlations regardless of whether the patient was hypothermic or normothermic. However, this study received a quality rating of 4 out of 12 .

Skin pigmentation. Three studies $(5$ oximeter trials) assessed how the degree of skin pigmentation affected the accuracy of pulse oximetry. Of these studies, only 1 study ( 2 oximeter trials) provided both the correlation statistic $(r=0.790$ and 0.810$)$ and data points $(\mathrm{N}=43)$. The mean unweighted and weighted $r$ was 0.800 (var $[r]=$ 0.0002 ). Cecil et al, 156 in a subset of their study population that was black ( 15 patients; 43 data points), demonstrated that both the Nellcor $\mathrm{N}-100$ (finger probe) and the Ohmeda 3700 (finger probe) oximeters had different regression lines from those in the total data set, with the Nellcor N-100 demonstrating a statistically significant difference from the standard IL282 co-oximeter. They suggested that the greater inaccuracy demonstrated by both oximeters over the inaccuracy seen in their total sample most likely was due to the wide range of pigmentation levels in the patients tested.
Hyperbilirubinemia. Hyperbilirubinemia was investigated in 3 studies ( 3 oximeter trials); however, only 1 study provided the correlation statistic $(r$ $=0.850$ ). Chaudhary and Burki ${ }^{127}$ compared oxygen saturation measurements, with use of the Hewlett Packard 47201A (ear probe) oximeter, with that derived from $\mathrm{SaO}_{2}$ saturation measurements in 11 patients with jaundice who had serum bilirubin concentrations between 2.7 and $35 \mathrm{mg} / 100 \mathrm{~mL}$. The correlation was 0.85 ; however, the $\mathrm{SaO}_{2}$ values were significantly underestimated.

\section{DISCUSSION}

For the 21 oximeter models included in the meta-analysis, the correlation coefficient $(r)$ ranged from 0.986 to 0.591 , with variability found even within the same model. Because pulse oximeters are calibrated empirically with use of observations taken from healthy volunteers, most models were found to be accurate within $2 \%$ ( \pm 1 SD) or $5 \%$ ( \pm 2 SD) of in vitro oximetry in the range of $70 \%$ to $100 \%$ $\mathrm{SaO}_{2}$ saturation. ${ }^{12,196}$ of the 23 studies (82 oximeter trials) for which bias and precision estimates were available, $42.68 \%$ underestimated $\mathrm{SaO}_{2}$, with a range of bias (precision) from $-13.20 \%(8.03)$ to $12.00 \%$ (13.30). $\mathrm{Spo}_{2}$ estimates below $70 \%$ oxygen saturation were relatively inaccurate. Readings from finger probes were more accurate than ear probes. This may be due to such factors as circulation time, probe specifications, and variations in cutaneous vasculature.

Pulse oximeters do have accuracy limitations, which clinicians must clearly understand to ensure that they are used most effectively. Pulse oximeters may fail to record accurately the true $\mathrm{SaO}_{2}$ during severe or rapid desaturation, during physiological extremes such as hypotension and hypothermia, during other unstable hemodynamic states, or with dyshemoglobinemia, vital dyes, low perfusion states, and motion. The most important criterion for pulse oximeters is that they effectively warn of dangerous levels of oxygen saturation and changes in pulse rate.

As expected, those studies involving healthy adult volunteers had the strongest aggregate mean correlation coefficient ( $r=0.957)$; whereas estimates obtained from respiratory and critically ill patients were weakest at 0.880 and 0.760 , respectively. Pulse oximetry has become an established monitoring technique for patients during anesthesia in the operating room, and it plays an important role in monitoring patients in the emergency department. ${ }^{197}$ Investigations have addressed the impact of routine clinical monitoring of oxygen sat- 
uration in the critically ill population, and important contributions have been made to the care of patients with compromised respiratory or hemodynamic conditions. Because critically ill patients are a heterogeneous cohort, it is difficult to isolate all parameters affecting the accuracy of pulse oximetry when used in critical care. ${ }^{27,198-200}$ Studies of pulse oximetry use in operating and recovery rooms have enough similarities with critical care that findings have been inferred to patient outcomes in critically ill patients. Further study is needed to determine the impact on pulse oximetry accuracy of such conditions as circulatory compromise from hypotension and vasoactive drugs.

In reviewing the studies for this meta-analysis, several issues arose. When the new method (pulse oximetry) was compared with the gold standard (in vitro saturation measurements from arterial blood samples), the degree of error of the new method was determined. Yet, both methods have a degree of uncertainty. First, there was considerable variation in the co-oximeters used in the primary studies included in the meta-analysis. There were 3 manufacturers (Radiometer, Ciba Corning, Instrumentation Laboratory) of 14 models of ABG analyzers, and 4 manufacturers (Instrumentation Laboratory, Ciba Corning, Radiometer, American Optical) of 7 models of co-oximeters. Second, co-oximeters also have a degree of error. They are reported to be accurate within $\pm 1.0 \%$ oxyhemoglobin $\left(\mathrm{O}_{2} \mathrm{Hb}\right)$ in the $\mathrm{SaO}_{2}$ range of $80 \%$ to $100 \%, 26,29$ but with a relatively high reported coefficient of variation $(\mathrm{CV}$ of $5.1 \% \pm 3.2 \%$ ). ${ }^{16}$ Also, the validity of the criterion measure used often was not reported. This variation in the standard used for comparison of pulse oximetry introduced a potential source of error in determining the overall aggregate mean estimate.

There are both technologic and physiological limitations to the accuracy of pulse oximetry. The accuracy of the $\mathrm{SpO}_{2}$ estimate is dependent on the empirical calibration curve programmed into the device, which is, in turn, only as accurate as the in vitro laboratory co-oximeter standard used to generate it. ${ }^{26,119}$ Also, an instrument error resides in the technology of pulse oximeters. The bias produced with pulse oximetry is related to the acquisition and processing of the data. Other sources of variation in the data are due to either betweensubject variation or within-subject variation. Between-subject variation depends on several factors, such as position of the probe, local circulation, $\mathrm{CoHb}$ and bilirubin levels, or intravenous dyes; whereas within-subject variation relates to transient conditions such as hemodynamic instability.
Because error is assumed constant in 1 subject with 1 oximeter, the degree of error is more accurately evaluated using continuous measures rather than absolute values.

Further sources of variation were identified in the primary studies. First, some studies were conducted with healthy volunteers; whereas others were carried out with patients in a variety of clinical settings under perhaps less than optimal conditions. Second, because pulse oximeters are empirically calibrated, the algorithm programmed into each oximeter undergoes a series of revisions. Earlier models versus later models would therefore tend to show less agreement between measures. However, the software revision used in the primary studies was not always specified. Third, missing data were a problem. Even though repeated paired samples were used in the primary studies, often either the sample size or number of data points (paired samples) were not reported.

When comparing methods, the data analyses in the primary studies usually involved a correlation coefficient $(r)$, with a significance value $(P)$, and a linear regression slope and intercept. The correlation coefficient is a measure of association, but not a measure of agreement. To determine the degree of confidence in pulse oximetry, Bland and Altman $^{83}$ recommended calculating the bias and precision between the 2 measures. Because many investigators only provided correlation coefficients or linear regression analyses, it was difficult to compare results in terms of accuracy without bias and precision estimates. There were no studies found that aggregated bias and precision estimates.

\section{CONCLUSION}

Continuous monitoring of arterial oxygen saturation with use of pulse oximetry is used in a variety of settings with a variety of patients to provide early detection of a decrease in oxygen saturation. However, several factors have been found to affect the accuracy of pulse oximetry. Pulse oximetry uses a photoplethysmographic signal to determine oxygen saturation, which is affected by pulse variations, as well as a variety of other physiological parameters. 4,201-204 Dark skin pigmentation, as well as high levels of CoHb, may cause overestimation of oxygen saturation. Measures of heart rate with use of pulse oximeters may be limited in the higher ranges, attributing to an underestimation of oxygen saturation in heavy exercise. Conditions of low perfusion or unstable hemodynamic states also affect the accuracy of oxygen saturation estimates. Although probe location is an 
issue, more recent results favor finger probes rather than ear probes.

The primary advantage of pulse oximeters is that they provide a continuous and noninvasive measurement of arterial oxygen saturation. This provides an opportunity for deviations from patients' baseline to be noticed, an early warning signal to clinicians to prevent the consequences of desatur ration, and an end-point to guide therapeutic interventions. It is important to realize, however, that pulse oximetry does not present a complete picture of oxygen transport. Information is not provided about hemoglobin concentration, cardiac output, efficiency of oxygen delivery to the tissues, the consumption or sufficiency of oxygenation, or adequacy of ventilation. ${ }^{205-207}$ Carbon dioxide tension and acid-base balance can only be obtained by $A B G$ analysis. Pulse oximetry is a valuable, noninvasive technology when combined with an understanding of its uses and limitations.

\section{REFERENCES}

1. Rutherford KA. Principles and application of oximetry. Crit Care Nurs Clin North Am 1989;1:649-57.

2. Szaflarski NL, Cohen NH. Use of pulse oximetry in critically ill adults. Heart Lung 1989; 18:444-55

3. Gilboy NS, MCGaffigan PA. Noninvasive monitoring of oxygenation with pulse oximetry. J Emerg Nurs 1989;15:26-31.

4. Schnapp LM, Cohen NH. Pulse oximetry: uses and abuses. Chest Cardiopulm J 1990;98:1244-50.

5. Welch IP. DeCesare $R$, Hess D. Pulse oximetry: instrumentation and clinical applications. Respir Care 1990;35:584-601

6. Severinghaus IW, Astrup PB. History of blood gas analysis; V: oxygen measurement. J Clin Monit 1986;2:174-89.

7. Severinghaus IW, Astrup PB. History and blood gas analysis; VI: oximetry. J Clin Monit 1986;2:270-88

8. Severinghaus JW, Honda Y. History of blood gas analysis; VII: pulse oximetry. J Clin Monit 1987;3:135-8

9. Hess D. Noninvasive monitoring in respiratory care-present, past, and future: an overview. Respir Care 1990;35:482-99.

10. Wukitsch MW, Petterson MT, Tobler DR, Pologe IA. Pulse oximetry: analysis of theory, technology, and practice. I Clin Monit 1988:4:290-301

11. East TD. What makes noninvasive monitoring tick?: a review of basic engineering principles. Respir Care 1990;35:500-19.

12. Kissinger DP, Hamilton IN, Rozycki GS. The current practice of pulse oximetry and capnometry/capnography in the prehospital setting. Emerg Care Quart 1991;7:44-50.

13. Huffman LM. Pulse oximetry: accuracy and clinical performance in different practice settings. J Am Assoc Nurs Anesth 1989:57:475-6

14. Mardirossian G, Schneider RE. Limitations of pulse oximetry. Anesth Prog 1992;39:194-6.

15. Mengelkoch LJ, Martin D, Lawler J. A review of the principles of pulse oximetry and accuracy of pulse oximeter estimates during exercise. Phys Ther 1994;74:40-9.

16. Hess D, Kacmarek RM. Techniques and devices for monitoring oxygenation. Respir Care 1993;38:646-71.

17. Harrahil M. Trauma notebook; pulse oximetry: pearls and pitfalls. J Emerg Nurs 1991:17:437-9.

18. Kelleher IF. Pulse oximetry. J Clin Monit 1989;5:37-62.
19. New W. Pulse oximetry versus measurement of transcutaneous oxygen. I Clin Monit 1985; 1:126-9

20 Taylor MB Whitwam IG. The current status of pulse oximetry. Anaesthesia 1986;41:943-9.

21. Pologe JA. Pulse oximetry: technical aspects of machine design. Int Anesth Clin: Adv Oxygen Monit 1987;25:137-53.

22. Severinghaus JW. History, status and future of pulse oximetry. Adv Exp Med Bio 1987;220:3-8.

23. Alexander CM, Teller LE, Gross JB. Principles of pulse oximetry: theoretical and practical considerations. Anesth Anal 1989;68:368-76.

24. Morris RW, Nairn M, Torda TA. A comparison of fifteen pulse oximeters. Part I: a clinical comparison; Part II: a test of performance under conditions of poor perfusion. Anesth Intensive Care 1989:17:62-73.

25. Tremper KK. Pulse oximetry. Chest 1989:95:713-5.

26. Tremper KK, Barker SJ. Pulse oximetry. Anesthesiology 1989.70:98-108.

27. Technology Subcommittee of the Working Group on Critical Care Ontario Ministry of Health. Noninvasive blood gas monitoring: a review for use in the adult critical care unit. Can Med Assoc J 1992;146:703-12.

28. Severinghaus JW, Kelleher JF. Recent developments in pulse oximetry. Anaesthesiology 1992;76:1018-38

29. Severinghaus IW. History and recent developments in pulse oximetry. Scand J Clin Lab Invest 1993;53(Suppl 214) 105-11

30. Dirks JL. Innovations in technology: continuous intra-arterial blood gas monitoring. Crit Care Nurs 1995;15:19-20,22,24-29.

31. Gaskin L, Thomas J . Pulse oximetry and exercise. Phys Ther 1995;81:254-61.

32. Lindberg LG, Lennmarken $C$, Vegfors $M$. Pulse oximetryclinical implications and recent technical developments. Acta Anaesthesiol Scand 1995;39:279-87.

33. Gramlich T. Pulse oximetry. Emergency 1992;24:25-7.

34. The Technology Assessment Task Force of the Society of Critical Care Medicine. A model for technology assessment applied to pulse oximetry. Crit Care Med 1993;21:615-24.

35. Runciman WB, Webb RK, Barker L, Currie M. The pulse oximeter: applications and limitations-an analysis of 2000 incident reports. Anaesth Intensive Care 1993;21:542-50.

36. Roizen MF Schreider B. Austin W. Carter C, Polk S. Pulse oximetry, capnography, and blood gas measurements: reducing cost and improving the quality of care with technology. I Clin Monit 1993;9:237-40

37. Hovagim AR, Backus WW, Manecke G, LaGasse R, Sidhu U, Poppers PI. Pulse oximetry and patient positioning: a report of eight cases. Anesthesiology 1989;71:454-6.

38. Duncan PG, Cohen MM. Pulse oximetry and capnography in anaesthetic practice: an epidemiological appraisal. Can I Anaesth 1991:38:619-25

39. Berels DJ, Marz MS. $\mathrm{SaO}_{2}$ monitoring in the postanesthesia care unit. J Post Anesth Nurs 1991;6:394-401

40. Gillies BS Posner K, Freund P, Cheney F. Failure rate of pulse oximetry in the postanesthesia care unit. I Clin Monit 1993:9:326-9.

41. DiBenedetto RJ, Graves SA, Gravenstein N, Konicek C. Pulse oximetry monitoring can change routine oxygen supplementation practices in the postanesthesia care unit. Anesth Analg 1994; $78: 365-8$

42. Moller IT, Pedersen T, Rasmussen LS, lensen PF, Pederson BD, Ralvo $\mathrm{O}$, et al. Randomized evaluation of pulse oximetry in 20,802 patients; I: design, demography, pulse oximetry failure rate, and overall complication rate. Anesthesiology 1993 78:436-44

43. Moller IT, Pedersen T, Rasmussen LS, Jensen PF, Pederson BD Ralvo $\mathrm{O}$, et al. Randomized evaluation of pulse oximetry in 20,802 patients; II: perioperative events and postoperative complications. Anesthesiology 1993;78:445-53.

44. Tyler IL, Tantisira B, Winter PM, Motoyama EK. Continuous monitoring of arterial oxygen saturation with pulse oxime 
try during transfer to the recovery room. Anesth Analg 1985:64:1108-12.

45. Griffiths DM, Ilsley AH, Runciman WB. Pulse meters and pulse oximeters. Anaesth Intensive Care 1988:16:49-53.

46. Morris RW, Buschman A, Warren D, Philip I, Raemer DB. The prevalence of hypoxemia detected by pulse oximetry during recovery from anesthesia. I Clin Monit 1988;4:16-20.

47. Iones RDM, Lawson AD, Gunawardene WMS, Roulson CJ, Brown AG, Smith ID. An evaluation of prolonged oximetric data acquisition. Anaesth Intensive Care 1992:20:303-7.

48. Moller IT. Anesthesia related to hypoxemia: the effect of pulse oximetry monitoring on perioperative events and postoperative complications. Dan Med Bull 1994;41:489-500.

49. Stausholm K, Rosenberg-Adamsen S, Edvardsen L, Kehlet $\mathrm{H}$, Rosenberg I. Validation of pulse oximetry for monitoring of hypoxaemic episodes in the late postoperative period. $\mathrm{Br} \mathrm{I}$ Anaesth 1997:78:86-7.

50. Peters K, Caulfield A, Schultz P, Miller C, Larson EL. Increasing clinical use of pulse oximetry. DCCN 1990;9:107-11.

51. Ahrens $\mathrm{T}$. Changing perspectives in the assessment of oxygenation. Crit Care Nurse 1993;13):78-83.

52. Szaflarski NL. Emerging technology in critical care: continuous intra-arterial blood gas monitoring. Am I Crit Care 1996:5:55-65

53. Misiano DR, Meyerhoff ME, Collinson ME. Current and future directions in the technology relating to bedside testing of critically ill patients. Chest 1990;97:204S 214 S.

54. Von Rueden KT. Noninvasive assessment of gas exchange in the critically ill patient. ACCN Clin Issues Crit Care Nurs 1990; : :239-47.

55. Bierman MI, Stein KL, Snyder JV. Pulse oximetry in the postoperative care of cardiac surgical patients: a randomized clinical trial. Chest 1992;22:278-81

56. Inman KJ, Sibbald WJ, Rutledge FS, Speechley M, Martin CM, Clark BJ. Does implementing pulse oximetry in a critical care unit result in substantial arterial blood gas savings? Chest Cardiopulm J 1993;104:542-6.

57. McCauley MD, Von Rueden KT. Noninvasive monitoring of the mechanically ventilated patient. Crit Care Nurs Quart 1988;11:36-49.

58. Jubran A, Tobin MJ. Reliability of pulse oximetry in titrating supplemental oxygen therapy in ventilator-dependent patients. Chest 1990;97:1420-25

59. Hess D. Noninvasive respiratory monitoring during ventilatory support. Crit Care Nurs Clin North Am 1991;3:565-74.

60. Brown $M$, Vender IS. Noninvasive oxygen monitoring. Crit Care Clin 1988:4:493-509

61. Partridge BL. Use of pulse oximetry as a noninvasive indicator of intravascular volume status. I Clin Monit 1987;3:263-8.

62. Tobin MJ. Respiratory monitoring during mechanical ventilation. Crit Care Clin 1990;6:679-709.

63. Zaloga GP. Evaluation of bedside testing options for the critical care unit. Chest 1990;97(Suppl 5):185S-190S.

64. Truwit ID, Rochester DF. Monitoring the respiratory system of the mechanically ventilated patient. New Horiz 1994;2: 94-106

65. Noll ML, Byers IF. Usefulness of measures of $\mathrm{SvO}_{2}, \mathrm{SpO}_{2}$, vital signs, and derived dual oximetry parameters as indicators of arterial blood gas variables during weaning of cardiac surgery patients from mechanical ventilation. Heart Lung 1995;24:220-7.

66. Pandit JJ. Accuracy of pulse oximetry in aortomyoplasty and balloon counterpulsation. Anaesthesia 1997:52:84-95.

67. Durren M. Clinical notebook: getting the most from pulse oximetry ] Emerg Nurs 1992:18:340-2

68. Narang VPS. Utility of the pulse oximeter during car diopulmonary resuscitation [letter|. Anesthesiology 1986;65:239-40.

69. Spittal MJ. Evaluation of pulse oximetry during cardiopulmonary resuscitation. Anaesthesia 1993:48:701-3.

70. Hinzmann CA, Budden PM, Olson I. Intravenous conscious sedation use in endoscopy: does monitoring of oxygen satum ration influence timing of nursing interventions? Gastroenterol Nurs 1992;15:6-13.

71. Wynne IW, Block AJ, Hemenway I, Hunt LA, Flick MR. Disordered breathing and oxygen desaturation during sleep in patients with chronic obstructive lung disease (COLD). Am I Med 1979;66:573-9.

72. Slutsky AS, Strohl KP. Quantification of oxygen saturation during episodic hypoxemia. Am Rev Respir Dis 1980;121: 893-5.

73. West $\mathrm{P}, \mathrm{George} \mathrm{CF}$, Kryger MH. Dynamic in vivo response characteristics of three oximeters: Hewlett-Packard 47201A, BIOX III, and Nellcor N-100. Sleep 1987:10:263-71.

74. Harris $C D$. Pulse oximetry: awakening the potential. RT: I Respir Care Practition 1994,7:51-52,54,56,58-62.

75. Williams JH, Powers SK, Stuart MK. Hemoglobin desaturation in highly trained athletes during heavy exercise. Med Sci Sports Exerc 1986;18:168-73

76. Lawler J, Landry G, Powers SK, Baker B, Dodd S, Richard RR. Accuracy of the Ohmeda 3700 pulse oximeter in estimating heart rate during exercise. Respir Care 1989:34:724-7.

77. McGovern IP, Sasse SA Stansbury DW, Causing LA, Light RW. Comparison of oxygen saturation by pulse oximetry and cooximetry during exercise testing in patients with COPD. Chest 1996:109:1151-5

78. Mackreth B. Assessing pulse oximetry in the field. I Emerg Med Serv 1990;15:56-57,59-60,62 passim

79. Aughey K, Hess D, Eitel D, Bleecher K, Cooley M, Ogden C, et al. An evaluation of pulse oximetry in prehospital care. Ann Emerg Med 1991;28:887-91

80. McGuire TJ. Pointer JE. Evaluation of a pulse oximeter in the prehospital setting. Ann Emerg Med 1988;17:1058-62.

81. Shrake K, Blonshine S, Brown R, Crapo R, Martineau R, Ruppell $G$, et al. AARC clinical practice guideline: pulse oximetry. Respir Care 1991;36:1406-9.

82. Kacmarek RM. Noninvasive monitoring of respiratory function outside of the hospital. Respir Care 1990;35:719-27.

83. Bland JM, Altman DG. Statistical methods for assessing agreement between two methods of clinical measurement. Lancet 1986;1:307-10

84. Barker SJ, Tremper KK. Pulse oximetry: applications and limitations. Int Anesth Clin 1987;25:155-75.

85. Eisenkraft JB. Pulse oximeter desaturation due to methemoglobinemia. Anesthesiology 1988;68:279-82.

86. Gottschalk A, Silverberg M. An unexpected finding with pulse oximetry in a patient with hemoglobin Köln. Anesthesiology 1994;80:474-6.

87. Glass KL, Dillard TA, Phillips YY, Torrington KG, Thompson IC. Pulse oximetry correction for smoking exposure. Mil Med 1996;161:273-6.

88. Kessler MR, Eide T, Humayun B, Poppers PI. Spurious pulse oximeter desaturation with methylene blue injection. Anesthesiology 1986:65:435-6

89. Scheller MS, Unger RJ, Kelner M]. Effects of intravenously administered dyes on pulse oximetry readings. Anesthesiology 1986;65:550-2.

90. Vegfors $M$, Lennmarken $C$. Carboxyhaemoglobin and pulse oximetry. Br I Anaesth 1991:66:625-6.

91. Cahan C, Decker MI, Hoekje PL, Strohl KP. Agreement between noninvasive oximetric values for oxygen saturation. Chest $\mathrm{Car}$ diopulm I 1990;97:814-9.

92. Bothma PA, Joynt GM, Lipman I, Hon H, Mathala B, Scribante $\mathrm{I}$, et al. Accuracy of pulse oximetry in pigmented patients. S Afr Med J 1996;86:594-6.

93. Chelluri L, Snyder JV, Bird JR. Accuracy of pulse oximetry in patients with hyperbilirubinemia. Resp Care 1991:36:1383-6.

94. Coté CJ, Goldstein A, Fuchsman WH, Hoaglin DC. The effect of nail polish on pulse oximetry. Anesth Analg 1988;67:683-6.

95. Fanconi S. Pulse oximetry for hypoxemia: a warning to users and manufacturers. Intensive Care Med 1989;15:540-2.

96. Webb RK. Ralston AC, Runciman WB. Potential errors in 
pulse oximetry; II: effects of changes in saturation and signal quality. Anaesthesia 1991;46:207-12.

97. Barker SJ, Hyatt J, Shah NK, Kao J. The effect of sensor malpositioning on pulse oximeter accuracy during hypoxemia. Anesthesiology 1993;79:248-54.

98. Strohl KP, House PM, Holic JF, Fouke JM, Cheung PW. Com parison of three transmittance oximeters. Med Instrum 1986;20:143-9.

99. Shimada Y, Yoshiya I, Oka N, Hamaguri K. Effects of multiple scattering and peripheral circulation on arterial oxygen saturation measured with a pulse-type oximeter. Med Bio Eng Comput 1984:22:475-8.

100. Kim I, Mathewson HS. Venous congestion affects arterial hemoglobin saturation measured by the pulse oximeter labstract]. Anesthesiology 1985;63:A174.

101. Kim I, Arakawa K, Benson KT, Fox DK. Pulse oximetry and circulatory kinetics associated with pulse volume amplitude measured by photoelectric plethysmography. Anesth Anal 1986;65:1333-9

102. Lawson D, Norley I, Korbon G, Loeb R, Ellis J. Blood flow limits and pulse oximeter signal detection. Anesthesiology 1987;67:599-603

103. Greenblott GB, Gerschultz S, Tremper KK. Blood flow limits and signal detection comparing five different models of pulse oximeters [letter]. Anesthesiology 1989;70:367-8.

104. Wilkins CJ, Moores M, Hanning CD. Comparison of pulse oximeters: effects of vasoconstriction and venous engorgement. Br J Anaesth 1989;62:439-44

105. Severinghaus JW, Spellman MJ. Pulse oximeter failure thresholds in hypotension and vasoconstriction. Anesthesiology 1990;73:532-7.

106. Vegfors $M$, Lindberg $L G$, Lennmarken $C$. The influence of changes in blood flow on the accuracy of pulse oximetry in humans. Acta Anesthesiol Scand 1992;36:346-9

107. Broome II, Mills GH, Spiers P, Reilly CS. An evaluation of the effect of vasodilatation on oxygen saturations measured by pulse oximetry and venous blood gas analysis. Anaesthesia 1993:48:415-6

108. Lindberg LG, Vegfors $M$, Lennmarken $C$, Oberg PA. Pulse oximeter signal at various blood flow conditions in an in vitro model. Med Bio Eng Comput 1994:33:87-91.

109. Secker C, Spiers P. Accuracy of pulse oximetry in patients with low systemic vascular resistance. Anaesthesia 1997;52:127 130.

110. Lazzell VA, Jopling MW. Accuracy of pulse oximetry in cyanotic congenital heart disease [abstract]. Anesthesiology 1987;67:A169.

111. Severinghaus JW, Koh SO. Effect of anemia on pulse oximeter accuracy at low saturation. J Clin Monit 1990;6:85-8.

112. Weston Smith SGW, Glass UH, Acharya J, Pearson TC. Pulse oximetry in sickle cell disease. Clin Lab Haematol 1989;11:185-8

13. Jay GD, Renzi FP. Evaluation of pulse oximetry in anemia from hemoglobin-H disease. Ann Emerg Med 1992;21:572-4

114. Plummer JL, Zakaria $A Z$, Ilsley AH, Fronsko RRL, Owen $H$. Evaluation of the influence of movement on saturation readings from pulse oximeters. Anaesthesia 1995;50:423-6.

115. Barker SI, Shah NK. The effects of motion on the performance of pulse oximeters in volunteers (revised publication). Anesthesiology 1997;86:101-8.

116. Dumas C, Wahr JA, Tremper KK. Clinical evaluation of a prototype motion artifact resistant pulse oximeter in the recovery room. Anesth Analg 1996;83:269-72

117. Brooks TD, Paulus DA, Winkle WE. Infrared heat lamps interfere with pulse oximeters [letter]. Anesthesiology 1984;61:630.

118. Hanowell L, Eisele JH Jr, Downs D. Ambient light affects pulse oximeters [letter]. Anesthesiology 1987;67:864 -5.

119. Ralston AC, Webb RK, Runciman WB. Potential errors in pulse oximetry; I: pulse oximeter evaluation. Anaesthesia 1991;46:202-6.
120. Hunter JE, Schmidt FL. Methods of meta-analysis. Newbury Park: Sage; 1990

121. Flick MR, Block AJ. In vivo continuous arterial oxygen saturation measurement by oximetry. Am Rev Respir Dis 1976;113(suppl): 126

122. Saunders NA, Powles ACP, Rebuck AS. Ear oximetry: accura cy and practicability in the assessment of arterial oxygenation. Am Rev Respir Dis 1976;1 13:745-9

123. Flick MR, Block AJ. Continuous in-vivo monitoring of arterial oxygenation in chronic obstructive lung disease. Ann Intern Med 1977;86:725-30.

124. Flick MR, Block AJ. Continuous in vivo measurement of arterial oxygen saturation by oximetry. Heart Lung 1977;6 $990-3$

125. Poppius H, Viljanen AA. A new ear oximeter for assessment of exercise-induced arterial desaturation in patients with pulmonary diseases. Scand J Respir Dis 1977;58:279-83.

126. Scoggin C, Nett L, Petty TL. Clinical evaluation of a new ear oximeter. Heart Lung 1977;6:121-6.

127. Chaudhary BA, Burki NK. Ear oximetry in clinical practice. Am Rev Respir Dis 1978:117:173-5.

128. Ishikawa $\mathrm{S}$, Linzmayer I, Segal MS. Clinical use of non-invasive method for determining oxygen saturation: ear oximetry. Ann Allergy 1978;41:18-20.

129. Douglas NJ, Brash HM, Wraith PK, Calverley PMA, Leggett RIE, McElderry L, et al. Accuracy, sensitivity to carboxyhemoglobin, and speed of response of the Hewlett-Packard $47201 \mathrm{~A}$ ear oximeter. Am Rev Respir Dis 1979;1 19:311-3

130. Sarnquist FH, Todd C, Whitcher C. Accuracy of a new noninvasive oxygen saturation monitor [abstract]. Anesthesiology 1980;53:S163.

I31. Yoshiya I, Shimada Y, Tanaka K. Spectrophotometric monitoring of arterial oxygen saturation in the fingertip. Med Bio Eng Comput 1980;18;27-32.

132. Cable JA. Evaluation of ear oximetry in the measurement of arterial oxygen saturation. J Am Osteopath Assoc $1981 ; 81: 107-12$

133. Knill RL, Clement JL, Kieraszewicz HT, Dodgson BG. Assessment of two noninvasive monitors of arterial oxygenation in anesthetized man. Anesth Analg 1982;61:582-6.

134. Fahey PI, Gruber S, Siska D, Leach B. Clinical evaluation of a new ear oximeter [abstract]. Am Rev Respir Dis 1983;127(4 part 2): 129

135. Petterson M, Winters I, Rudolph C, Cecil W. Clinical evaluation of the BIOX IIA ear oximeter in adult intensive care and post-open heart surgery patients [abstract]. Respir Care $1983 ; 28: 1348$

136. Yelderman M, New W. Evaluation of pulse oximetry. Anesthesiology 1983;59:349-52.

137. Kim SK, Baidwan BS, Petty TL. Clinical evaluation of a new finger oximeter. Crit Care Med 1984,12:910-2.

138. Shippy MB, Petterson MT, Whitman RA, Shivers CR. A clinical evaluation of the BTI BIOX II ear oximeter. Respir Care 1984;29:730-5

139. Shulman MS, Brodsky IB, Mark JBD, Swan M. Non-invasive pulse-oximetry during one-lung ventilation [abstract]. Anesthesiology 1984,61:A98.

140. Brodsky JB, Shulman MS, Swan M, Mark JBD. Pulse oximetry during one-lung ventilation. Anesthesiology 1985;63:212 4.

141. Cecil WT, Petterson MT, Lamoonpun S, Rudolph CD. Clinical evaluation of the Biox IIA ear oximeter in the critical care environment. Respir Care 1985;30:179-83.

142. Mackenzie N. Comparison of a pulse oximeter with an ear oximeter and an in-vitro oximeter. I Clin Monit 1985;1:156-60.

143. Mihm FG, Halperin BD. Noninvasive detection of profound arterial desaturation using a pulse oximetry device. Anesthesiology 1985;62:85-7.

144. Ries AL, Farrow JT, Clausen JL. Accuracy of two ear oximeters at rest and during exercise in pulmonary patients. Am Rev Respir Dis 1985:132:685-9.

145. Tremper KK, Hufstedler SM, Barker SJ, Adams AL, Wong DH, 
Zaccari I, et al. Accuracy of a pulse oximeter in the critically ill adult: effect of temperature and hemodynamics [abstract]. Anesthesiology 1985;63:A175.

146. Tweeddale PM, Douglas NI. Evaluation of the Biox IIA ear oximeter. Thorax 1985:40:825-7.

147. Chapman KR, Liu FLW, Watson RM, Rebuck AS. Range of accuracy of two wavelength oximetry. Chest 1986;89:540-2.

148. Smyth RJ, D'Urzo AD, Slutsky AS, Galko BM, Rebuck AS. Ear oximetry during combined hypoxia and exercise. J Appl Physiol $1986 ; 60: 716-9$

149. Tytler JA, Seeley HF. The Nellcor N-101 pulse oximeter: a clinical evaluation in anesthesia and intensive care. Anaesthesia 1986:41:302-5.

150. Hansen IE, Casaburi R. Validity of ear oximetry in clinical exercise testing. Chest 1987;91:333-7.

151. Hess D, Mohlman A, Kochansky M, Kriss T. An evaluation of the accuracy of the Physio-Control Lifestat 1600 pulse oximeter in measuring arterial oxygen saturation. Respir Care 1987;32:19-23.

152. Kagle DM, Alexander CM, Berko RS, Giuffre M, Gross IB. Evaluation of the Ohmeda 3700 pulse oximeter: steady-state and transient response characteristics. Anesthesiology 1987;66:376-80

153. Severinghaus IW, Naifeh KH. Accuracy of response of six pulse oximeters to profound hypoxia. Anesthesiology 1987;67:551 -8.

154. Viitanen A, Salmenpera M, Heinonen I. Noninvasive monitoring of oxygenation during one-lung ventilation: a comparison of transcutaneous oxygen tension measurement and pulse oximetry. J Clin Monit 1987;3:90-5

155. Warley ARH, Mitchell $\mathrm{JH}$, Stradling JR. Evaluation of the Ohmeda 3700 pulse oximeter. Thorax 1987;42:892-6

156. Cecil WT, Thorpe KI, Filbuch EE, Tuohy GF. A clinical evaluation of the accuracy of the Nellcor $\mathrm{N}-100$ and the Ohmeda 3700 pulse oximeters. J Clin Monit 1988:4:31-6.

157. Gabrielczyk MR, Buist RJ. Pulse oximetry and postoperative hypothermia: an evaluation of the Nellcor $\mathrm{N}-100$ in a cardiac surgical intensive care unit. Anaesthesia 1988:43:402-4

158. Iones I. Heiselman D. Cannon L, Gradisek R. Continuous emergency department monitoring of arterial saturation in adult patients with respiratory distress. Ann Emerg Med $1988 ; 17: 463-8$

159. Kurki T, Smith NT, Sanford T. Pulse oximetry during open heart surgery [abstract]. Anesth Analg 1988;67:S123.

160. Mendelson Y, Kent IC, Yocum BL, Birle MI. Design and evaluation of a new reflectance pulse oximeter sensor. Med Instrum 1988;22:167-73.

161. Mendelson Y, Kent JC, Shahnarian A, Welch GW, Giasi RM. Evaluation of the Datascope ACCUSAT pulse oximeter in healthy adults. I Clin Monit 1988:4:59-63.

162. Nickerson $B G$, Sarkisian $C$, Tremper $K$. Bias and precision of pulse oximeters and arterial oximeters. Chest 1988;93. 515-7.

163. Niehoff J, Del Guercio C, La Morte W, Hughes-Grasberger SL, Heard S, Dennis R, et al. Efficacy of pulse oximetry and capnometry in postoperative ventilatory weaning. Crit Care Med 1988; 16:701-5

164. Tashiro C, Koo YH, Fukumitsu K, Tomi K, Mashimo T, Yoshiya I. Effects of carboxyhemoglobin on pulse oximetry in humans. I Anesth 1988;2:36-40

165. Taylor MB, Whitwam JG. The accuracy of pulse oximeters: a comparative clinical evaluation of five pulse oximeters. Anaesthesia 1988:43:229-32.

166. Choe H, Tashiro C, Fukumitsu K, Yagi M, Yoshiya I. Compari son of recorded values from six pulse oximeters. Crit Care Med 1989;17:678-81.

167. Decker MJ, Hoekje PL, Strohl KP. Ambulatory monitoring of arterial oxygen saturation. Chest 1989;95:717-22.

168. Palve $\mathrm{H}$, Vuori A. Pulse oximetry during low cardiac output and hypothermia states immediately after open heart surgery. Crit Care Med 1989;17:66-9.
169. Powers SK, Dodd S, Freeman J, Ayers GD, Samson H, McKnight T. Accuracy of pulse oximetry to estimate $\mathrm{HbO}_{2}$ fraction of total Hb during exercise. I Appl Physiol 1989;67:300-4

170. Ries AL, Prewitt LM, Johnson JI. Skin color and ear oximetry. Chest 1989;96:287-90.

171. Severinghaus JW, Naifeh KH, Koh SO. Errors in 14 pulse oximeters during profound hypoxia. I Clin Monit 1989;5:7281

172. Veyckemans F, Baele P, Guillaume JE, Willems E, Robert A, Clerbaux T. Hyperbilirubinemia does not interfere with hemoglobin saturation measured by pulse oximetry. Anesthesiology 1989;70:118 22

173. Barthelemy JC, Geyssant A, Riffat J, Antoniadis A, Berruyer J, Lacour JR. Accuracy of pulse oximetry during moderate exercise: a comparative study. Scan I Clin Lab Invest 1990;50 533-9.

174. Brown DD, Knowlton RG, Szurgot BT, Sanjabi PB. Validity of pulse ear oximetry for determining oxygen hemoglobin saturation during exercise [abstract]. Med Sci Sports Exerc 1990;22:S54.

175. Desiderio DP, Wong G, Shah NK, Liu J, Loughlin Cl, Bedford RF. A clinical evaluation of pulse oximetry during thoracic surgery. I Cardiothorac Anesth 1990;4:30-4

176. Escourrou PJL, Delaperche MF, Visseaux A. Reliability of pulse oximetry during exercise in pulmonary patients. Chest 1990:97:635-8

177. Peters K, Cauifield A, Schultz P, Miller C, Larson EL. Increasing clinical use of pulse oximetry. DCCN 1990:9:107-11

178. Warren $\mathrm{G}$, Cureton K, Middendorf W, Ray C, Warren J. Validity and reliability of pulse oximetry in highly trained endurance athletes [abstract]. Int J Sports Med 1990;1 1:405.

179. Chelluri L, Snyder JV. Bird JR. Accuracy of pulse oximetry in patients with hyperbilirubinemia. Respir Care 1991;36: 1383-6

180. Clayton DG, Webb RK, Ralston AC, Duthie D, Runciman WB. A comparison of the performance of 20 pulse oximeters under conditions of poor perfusion. Anaesthesia 1991;46: 3- 10.

181. Hannhart B, Haberer IP, Saunier C, Laxenaire MC. Accuracy and precision of fourteen pulse oximeters. Eur Respir 1991:4:115-9

182. Hannhart B, Michalski H, Delorme N Chapparo G. Polu J. Reliability of six pulse oximeters in chronic obstructive pulmonary disease. Chest 1991;99:842-6.

183. Ibanez J, Velasco J, Raurich IM. The accuracy of the Biox 3700 pulse oximeter in patients receiving vasoactive therapy. Intensive Care Med 1991;17:484-6.

184. Modica R, Rizzo A. Accuracy and response time of a portable pulse oximeter: the Pulsox -7 with a finger probe. Respiration 1991:58:155-7.

185. Palve $\mathrm{H}$, Vuori $\AA$. Accuracy of three pulse oximeters at low cardiac index and peripheral temperature. Crit Care Med $1991 ; 19: 560-2$.

186. Palve $\mathrm{H}$, Vuori A. Minimum pulse pressure and peripheral temperature needed for pulse oximetry during cardiac surgery with cardiopulmonary bypass. J Cardiothorac Vasc Anesth 1991.5:327-30.

187. Stewart KG, Rowbottom SI. Inaccuracy of pulse oximetry in patients with severe tricuspid regurgitation. Anaesthesia 1991;46:668-70

188. Withington DE, Ramsay IG, Saoud AT, Bilodeau J. Weaning from ventilation after cardiopulmonary bypass: evaluation of a non-invasive technique. Can J Anaesth 1991;38:15-9.

189. Martin D, Powers S, Cicale M, Collop N, Huang D, Criswell D. Validity of pulse oximetry during exercise in elite endurance athletes. J Appl Physiol 1992;72:455-8.

190. Mengelkoch L, Martin D, Cicale M, Huang D. Validity of pulse oximetry during maximal treadmill exercise [abstract]. Med Sci Sports Exerc 1992:24:S159.

191. Norton LH, Squires B, Craig NP, McLeay G, McGrath P, 
Norton KI. Accuracy of pulse oximetry during exercise stress testing. Int I Sports Med 1992; 13:523-7.

192. Palve $H$. Reflection and transmission pulse oximetry during compromised peripheral perfusion. J Clin Monit 1992;8: $12-5$

193. Wong DH, Wier P, Mahutte CK, Onishi R, Daves S, Foran W, et al. Experimental and predicted dual oximetry variability. I Clin Monit 1993;9:268-74

194. Thrush D, Hodges MR. Accuracy of pulse oximetry during hypoxemia. South Med I 1994;87:518-21

195. Clayton DG, Webb RK, Ralston AC, Duthie D, Runciman WB. Pulse oximeter probes: a comparison between finger, nose, ear and forehead probes under conditions of poor perfusion. Anaesthesia 1991;46:260-5.

196. de Kock IP, Tarassenko L. In vitro investigation of the factors affecting pulse oximetry. I Biomed Engin 1991;13:6I-6.

197. Galdun JP, Paris PM, Stewart RD. Pulse oximetry in the emergency department. Am I Emerg Med 1989;7:422-5.

198. Scheller J. Loeb R. Respiratory artifact during pulse oximetry in critically ill patients. Anesthesiology 1988;69:602-3.

199. Sipe S, Boyd G, Battito M, Bradley E. High "failure" rate for pulse oximetry in patients with chronic renal failure [abstract]. Crit Care Med 1992;20(Suppl):S21.
200. Grossbach I. Case studies in pulse oximetry monitoring. Crit Care Nurs 1993:13:63-5.

201. Ries AL. Oximetry--know thy limits. Chest 1987;91:316.

202. Grace RF. Pulse oximetry: gold standard or false sense of security? Med J Aust 1994;160:638-44

203. Ralston AC, Webb RK, Runciman WB. Potential errors in pulse oximetry; III: effects of interference, dyes, dyshaemoglobins and other pigments. Anaesthesia 1991;46:291-5.

204. Messina BAM. Pulse oximetry: assessing accuracy. I Post Anesth Nurs 1994:9:228-31.48

205. Pierson DJ. Pulse oximetry versus arterial blood gas specimens in long-term oxygen therapy. Lung 1990;168(Suppl): $782-8$

206. Myburgh IA. Derived oxygen saturations are not clinically useful for the calculation of oxygen consumption. Anaesth Intens Care 1992;20:460-3.

207. Johnson PA, Bihari DJ, Raper RF, Haughton MA, Fisher MM Herkes RG. A comparison between direct and calculated oxy gen saturation in intensive care. Anaesth Intens Care 1993;21:72-5

\section{ON THE MOVE?}

Send us your new address at least six weeks ahead

Don't miss a single issue of the journal! To ensure prompt service when you change your address, please photocopy and complete the form below.

Please send your change of address notification at least six weeks before your move to ensure continued service. We regret we cannot guarantee replacement of issues missed due to late notification.

JOURNAL TITLE:

Fill in the title of the journal here.

OLD ADDRESS:

Affix the address label from a recent issue of the journal here.

\section{NEW ADDRESS:}

Clearly print your new address here.

Name

Address

City/State/ZIP
COPY AND MAIL THIS FORM TO:

Journal Subscription Services

Mosby-Year Book, Inc.

11830 Westline Industrial Dr.

St. Louis, MO 63146-3318
OR FAX TO:

$314-432-1158$

NM Mosby
OR PHONE:

1-800-453-4351

Outside the U.S., call

314-453-4351 